Article

\title{
Empirical, Dimensional and Inspectional Analysis in the Design of Bottom Intake Racks
}

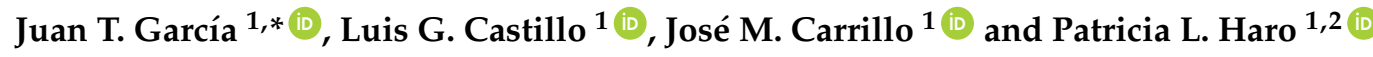 \\ 1 Civil Engineering Department, Universidad Politécnica de Cartagena, Paseo Alfonso XIII, 52, \\ Cartagena 30203, Spain; luis.castillo@upct.es (L.G.C.); jose.carrillo@upct.es (J.M.C.); \\ patricia.haro@epn.edu.ec (P.L.H.) \\ 2 Civil and Environmental Engineering Department, Escuela Politécnica Nacional, \\ Ladrón de Guevera E11-253, Quito 170517, Ecuador \\ * Correspondence: juan.gbermejo@upct.es; Tel.: +34-968-327-026
}

Received: 11 July 2018; Accepted: 1 August 2018; Published: 4 August 2018

\begin{abstract}
Flow over bottom racks is highly turbulent, three-dimensional and spatially varied. The design of bottom intake systems has mainly been studied in the laboratory. The comparison of existing experimental studies shows large deviations in the definition of design parameters such as wetted rack length. Each experimental study is limited to a single bar type or to a low range of void ratios, which makes it difficult to generalize the observed data. A combination of empirical, dimensional and inspectional analysis is presented as a useful tool to reduce the number of variables with influence in the design parameters, such as the wetted rack length or the mean discharge coefficient. This work includes a broad experimental campaign in which wetted rack length and mean discharge coefficient are characterized using five different bottom racks with different void ratios (area between bars divided by total area). T-shaped flat and circular bars are considered as well as five different longitudinal slopes. Empirical and inspectional analyses have allowed us to verify, in two different ways, the relation between wetted rack length and incoming flow through potential functions. The influence of the viscous forces has been studied as a function of the incoming flow. Similar results may be obtained when analysing the Froude number at the beginning of the rack, depending on the wetted rack length. A new formulation for calculating the mean discharge coefficient and wetted rack length is proposed.
\end{abstract}

Keywords: empirical analysis; dimensional analysis; inspectional analysis; bottom rack; mean discharge coefficient; rack length

\section{Introduction}

The design of bottom intakes to derive flow at stepped rivers has been broadly studied by hydraulic engineers. The definition of parameters such as the discharge coefficient and the wetted length of the racks in the laboratory-with clear water-have been analysed with the support of empirical and dimensional analysis. Empirical data of at least 13 hydraulic structures and scale models are available in the literature. Those studies have void ratios (spacing between bars divided by the total area) from 0.095 to 0.66 , and incoming flows from 0.05 to $0.20 \mathrm{~m}^{3} / \mathrm{s} / \mathrm{m}$. Different bar shapes have been considered: works of Noseda [1,2] Castillo et al. [3], Castillo et al. [4], García [5,6] and Carrillo et al. [7] used T-shaped flat bars; Garot [8], Righetti et al. [9], Ghosh and Ahmad [10] and Kumar et al. [11] analyzed prismatic rounded and flat bars; Brunella et al. [12], Vargas [13] and Subramanya [14] presented results with circular bars; Orth et al. [15] and White et al. [16] experimented with hydrodynamic bars; and Nakagawa [17] and Bina [18] used mesh-panel bottom racks. At prototype scale, Drobir [19] presented the only existing measurements of wetted rack 
length. Other authors include qualitative considerations observed at prototype bottom systems like Ract-Madoux et al. [20]; Bouvard [21]; Raudkivi [22]; and Drobir [23]. Some authors included theoretical equations and empirical adjustments from others' experimental data, such as De Marchi [24]; Krochin [25]; Mostkow [26]; Frank [27]; and Bouvard and Kuntzmann [28]. Experimental works including clear water and sediments are nowadays being considered when studying occlusion in bottom racks, such as experiments from Krochin [25]; Castillo et al. [29]; Castillo et al. [30]; Bina and Shaghi [31]. From the computational fluid dynamics field, general good agreement was found between laboratory data and numerical modelsflow profiles over the rack using different bar types and rack slopes like those collected in Carrillo et al. [7,32]. Those techniques may help to obtain a better understanding of this flow type.

Despite this, the hydraulics of these structures still have numerous issues that need to be better addressed [12]. The influence of the shape and bar spacing in the derived flow, as well as the adopted longitudinal slope still need to be clarified and generalized for a correct design of these structures. Experimental works have usually been developed in a specific range that makes it difficult to extrapolate results. For instance, each author has only used a single type of bar or only one separation between them which thus does not facilitate the use of the results for other studies. To clarify this, Drobir [23] proposed a technical guide for the design of bottom racks where the rack length was obtained from experimental works of Noseda [1,2] and Frank [33]. Drobir [23] considered T-shaped bars, void ratios smaller than 0.30 , and flow rates up to $0.20 \mathrm{~m}^{3} / \mathrm{s} / \mathrm{m}$. Vargas [13] carried out the comparison of rack lengths of circular bars with void fractions of $0.33-0.50$ and flow rates up to $0.04 \mathrm{~m}^{3} / \mathrm{s} / \mathrm{m}$ : The author obtained differences of up to twofold for the design of a bottom rack with void ratio $m=0.60$ and specific flow rates $q=1.25 \mathrm{~m}^{3} / \mathrm{s} / \mathrm{m}$. Similar conclusions were observed by Brunella et al. [12], observing a difference around $50 \%$ of the rack length for circular bars, with void ratios of 0.664 , and flows up to $0.20 \mathrm{~m}^{3} / \mathrm{s} / \mathrm{m}$.

The results obtained with a specific rack could be extrapolated [23] to other types of racks with remarkable errors. For the design of a specific bottom intake, an experimental campaign should be done maintaining similar void ratios to the proposed in the field prototype and it would be recommended to analyze flow rate up to $0.2 \mathrm{~m}^{3} / \mathrm{s} / \mathrm{m}$. To obtain general rack lengths, it seems necessary to have a wide range of bottom racks flow rate measurements with different kinds of bar types and void ratios.

Besides this, the flow over bottom intake racks are three-dimensional and spatially varied, presenting interactions with bottom bars; these racks are also highly turbulent. In order to address the problem in a simplified way, it is normally assumed that flux is one-dimensional, there is hydrostatic pressure distribution, and the energy head remains constant.

The orifice equation relates the derived flow with the area of the orifice, the available energy upstream of the orifice and the discharge coefficient using the orifice equation, considering that the derived flow will be subtracted from the principal flow, and together with the derivative of the energy equation, the water surface profile may be obtained, while the discharge coefficient is usually adjusted with the hypothesis of no dissipation energy along the rack and from adjustments of experimental data. This approach does not allow the correct definition of the wetted rack length required to calculate the total flow derived. Most of the flux sticks to the bar due to surface tension [19], which the previous formulation does not include (Figure 1). At the beginning of the rack, the discharge through bottom racks is principally due to gravitational forces that can be considered by Froude number and geometrical parameters of discharge [34].

However, as the flow is spatially varied, the water depth and flow rate decrease along the rack. There is also a remarkable curvature of the free surface. Hence, the surface tension should not be neglected, and the Weber number may be taken into account (Figure 2). The viscosity forces are important at small Reynolds numbers. For instance, Brunella et al. [12] considered that Reynolds number when calculated assuming critical conditions with values lower than 250,000 would be affected by scale effects. Thus the evaluation of these parameters should be considered when characterizing the wetted rack length. 

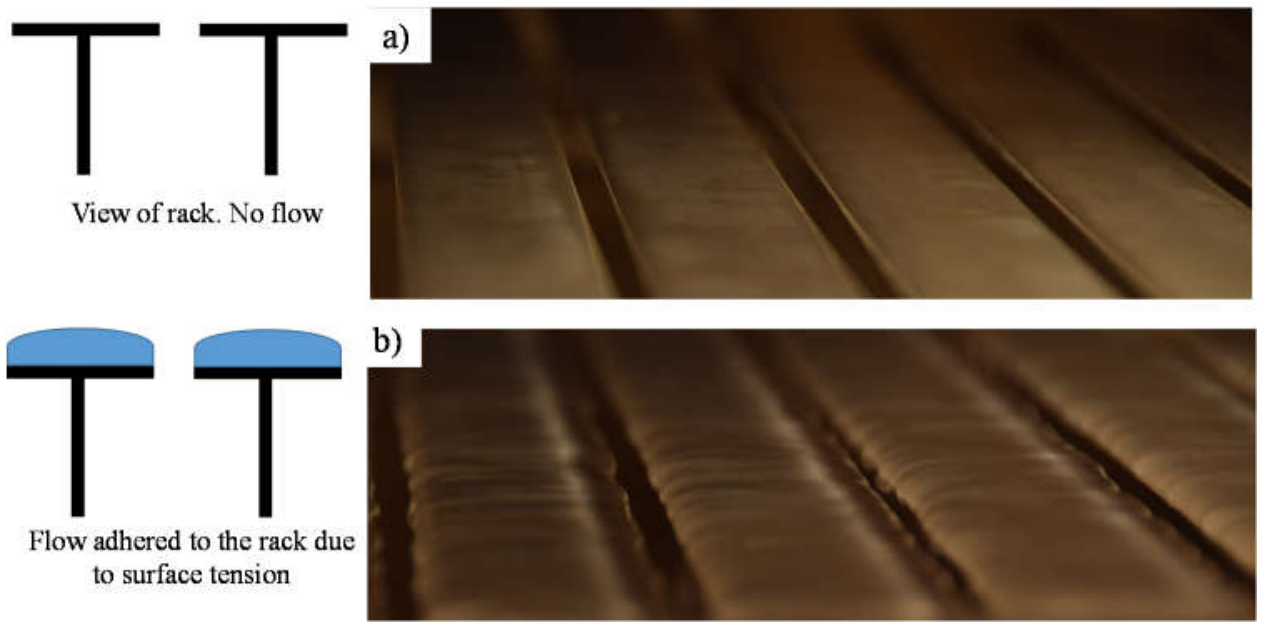

Figure 1. View of the final section of the bottom rack with T-shaped bars with void ratio $m=0.16$ and spacing between bars of $5.7 \mathrm{~mm}$ in two different cases: (a) no flow; (b) flow adhered to the rack due to surface tension.

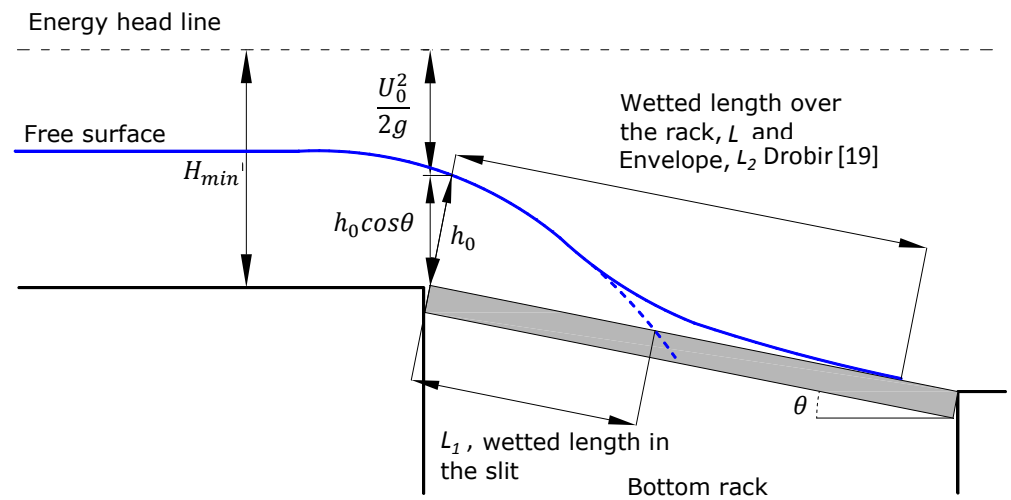

Figure 2. Scheme of the spatially varied flow over bottom intake system.

Empirical formulas are based on experimental measurements. Those expressions have been used in designing hydraulic structures and in predicting the behavior of the flow with engineering judgment, through trial and error processes [34].

Inspectional analysis operates with the set of equations describing the hydrodynamic force balances. This includes any type of equation that mathematically represents a physical phenomenon [35].

Dimensional analysis has allowed for the incorporation of variables into a basic dimensionless expression that experience has shown to be essential. The functional relationship of several members of this expression is then developed or approximated [36]. Dimensional analysis is performed through the Buckingham $\pi$ theorem [36]. The theorem states that if there is a physically meaningful equation involving a certain number $n$ of physical variables, then the original equation can be rewritten in terms of a set of $p=n-k$ dimensionless parameters called $\pi_{1}, \pi_{2}, \ldots, \pi_{\mathrm{p}}$, obtained from the original variables. The Buckingham $\pi$ theorem provides a method for computing sets of dimensionless parameters from given variables, even if the form of the equation remains unknown.

A combination of dimensional, inspectional and empirical analyses help to obtain a correct function to interpret the phenomena of flow.

This work includes a broad experimental campaign where wetted rack length, $L$, and mean discharge coefficient, $\overline{C_{q H}}$, are characterized using five different bottom racks with different void ratios, $m$ (area between bars divided by total area) of $0.16,0.22,0.28$ and 0.60 . Two different types of bars, 
T-shaped flat and circular bars, are employed. Five different longitudinal slopes: $0 ; 10 ; 20 ; 30 ;$ and 33\% have been considered. The specific flow rate, $q$, covers the range from 0.05 to $0.20 \mathrm{~m}^{3} / \mathrm{s} / \mathrm{m}$.

Dimensional, empirical and inspectional analyses are taken to define variables such as wetted rack length and discharge coefficient, which influence the design parameters of bottom rack systems.

Equations to define the mean discharge coefficient in different conditions have been obtained by using the least square fitting tool of Microsoft Excel spreadsheet. Those expressions allow bottom intake structures to be designed.

\section{Wetted Rack Length L and Mean Discharge Coefficient $\overline{C_{q H}}$}

The wetted rack length is defined as the maximum length reached by the flow over a rack to completely derive the incoming flow (Figure 2). This is an important design parameter of the racks. This length was proposed by Drobir [19] with an envelope of field measurements and it was defined as $L_{2}$. Additionally, Drobir defined the length scale, $L_{1}$, as the distance where the flow depth disappears in the slit between two bars. As an example of the rack slope influence in the wetted rack length, Figures 3 and 4 show the wetted rack length, $L$, and its variation when different longitudinal slopes are considered. In both cases, the inlet flow and the void fraction are the same. Wetted rack length is usually measured experimentally in the laboratory. Knowing it, the mean discharge coefficient, $\overline{C_{q H}}$, may be calculated from the orifice equation, once this equation is integrated along the wetted rack length:

$$
\overline{C_{q H}}=\frac{q}{L m \sqrt{2 g H_{\text {min }}}}
$$

where $q$ is the flow derived by the rack; $L$ the wetted rack length; $m$ the void ratio, $\overline{C_{q H}}$ the mean discharge coefficient for each wetted rack length; $g$ the gravitational acceleration; and $H_{\text {min }}$ the minimum energy head calculated as $1.5 h_{c}$, with $h_{c}$ being the critical depth and referred to the plane of the rack.
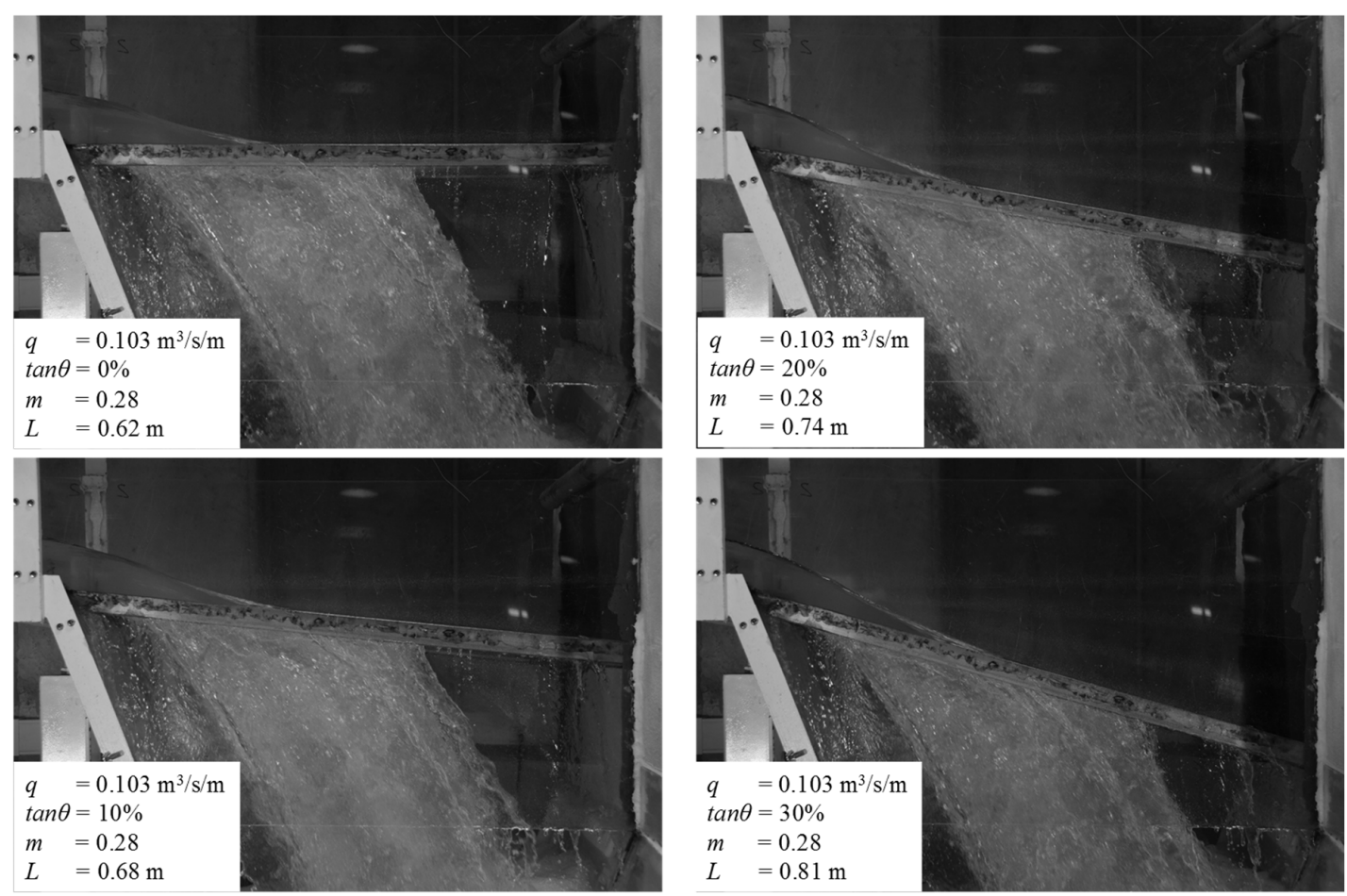

Figure 3. Wetted rack length for different flows and longitudinal slopes with racks made of circular bars and void ratio $m=0.28$. 

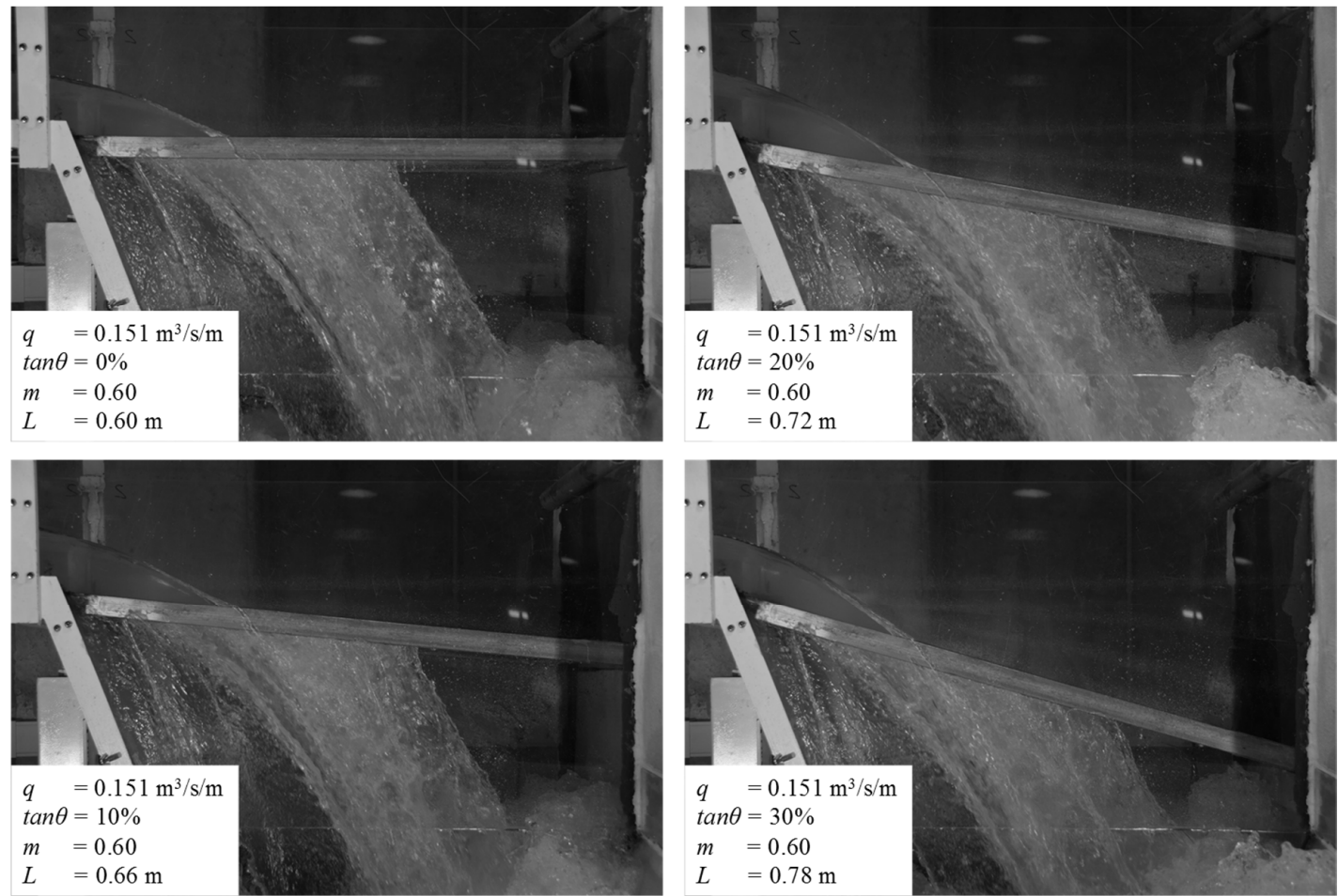

Figure 4. Wetted rack length for different flows and longitudinal slopes with racks made of circular bars and void ratio $m=0.60$.

Comparing values of wetted rack lengths proposed by different authors, this length may differ by up to double in some cases [4-6]. This is principally due to the variation of the experimental conditions used to adjust the discharge coefficient, such as the shape and width of the bars, the spacing between them, the void ratio, the approximation flow conditions, the initial flow depth $h_{0}$, or the longitudinal rack slope, $\tan \theta,[4-7]$.

\section{Physical Device}

The physical device consists in an intake system based on Noseda's [1,2] physical model (Figure 5). The inlet is a $5.00 \mathrm{~m}$ long and $0.50 \mathrm{~m}$ wide channel with methacrylate walls. At the end of the channel there is a bottom rack intake system with different slopes (from horizontal to $33 \%$ ). The racks were built with aluminium bars with T-shaped flat and circular profiles. The rack length is $0.90 \mathrm{~m}$ in the flow direction. Bars are longitudinally oriented with the flow direction. Table 1 presents the characteristics of the racks used in the present work [4-7,32].

Table 1. Characteristics of the racks tested.

\begin{tabular}{|c|c|c|c|c|c|c|c|}
\hline $\begin{array}{l}\text { Length } \\
\text { (m) }\end{array}$ & $\begin{array}{l}\text { Width } \\
b_{w}(\mathrm{~m})\end{array}$ & $\begin{array}{l}\text { Bar Type } \\
\text { (mm) }\end{array}$ & $\begin{array}{l}\text { Width of the } \\
\text { Bars (mm) }\end{array}$ & $\begin{array}{l}\text { Direction of } \\
\text { the Bars }\end{array}$ & $\begin{array}{c}\text { Spacing } \\
\text { between Bars, } \\
b_{1}(\mathrm{~mm})\end{array}$ & $\begin{array}{l}\text { Void Ratio } \\
m=\frac{b_{1}}{b_{1}+b_{w}}\end{array}$ & $\begin{array}{c}\text { Longitudinal } \\
\text { Slope }(\%)\end{array}$ \\
\hline \multirow{5}{*}{0.90} & \multirow{5}{*}{0.50} & $\mathrm{~T} 30 / 25 / 2$ & \multirow{5}{*}{30} & \multirow{5}{*}{ Longitudinal } & 5.7 & 0.16 & \multirow{5}{*}{$0,10,20,30,33$} \\
\hline & & $\mathrm{T} 30 / 25 / 2$ & & & 8.5 & 0.22 & \\
\hline & & T30/25/2 & & & 11.7 & 0.28 & \\
\hline & & $\mathrm{O} 30 / 30$ & & & 11.7 & 0.28 & \\
\hline & & $\mathrm{O} 30 / 30$ & & & 45.0 & 0.60 & \\
\hline
\end{tabular}




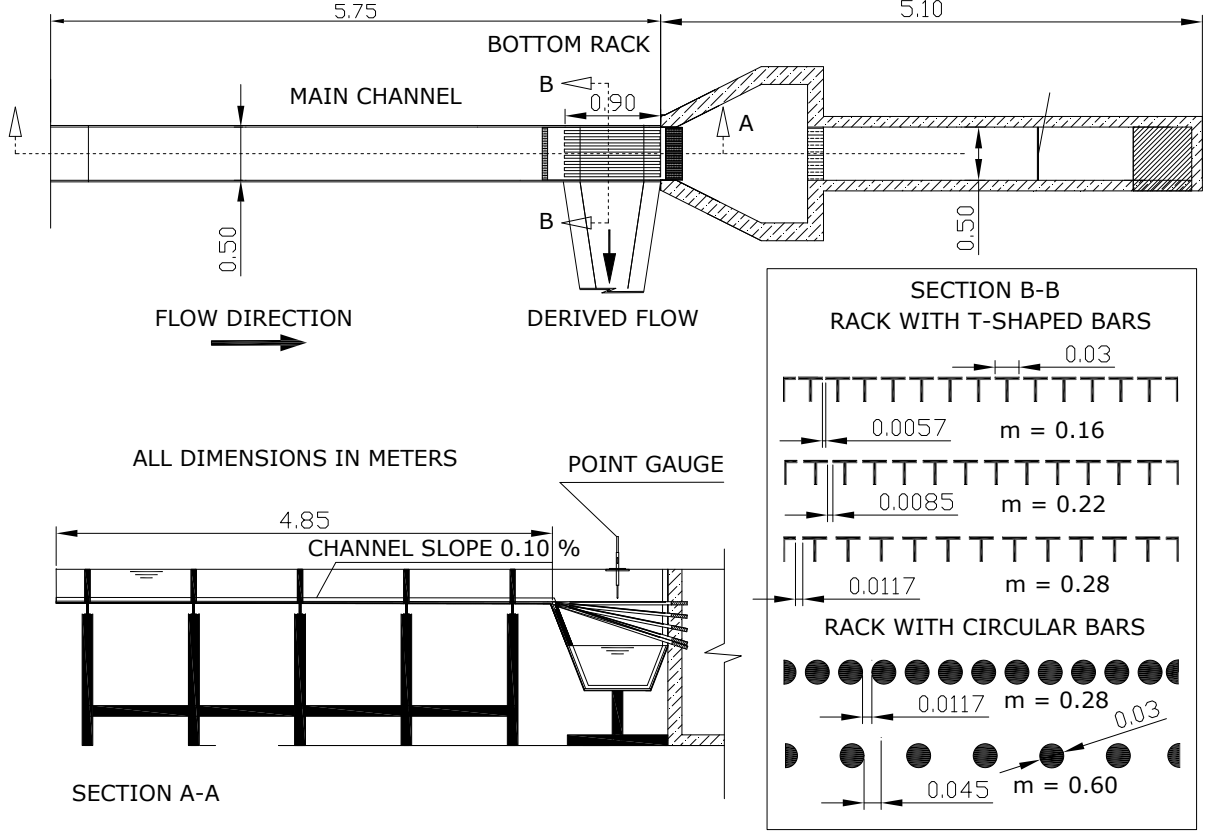

Figure 5. Scheme of the intake system physical device.

In each test, the water depth at the beginning of the rack, $h_{0}$, and the wetted rack length were measured with a vertical point gauge (accuracy $\pm 0.5 \mathrm{~mm}$ in vertical and $\pm 1.0 \mathrm{~mm}$ in horizontal) as shown in Figure 2. The point gauge measures only vertical distances. To define the water depth at the beginning of the rack, $h_{0}$, it was necessary to measure several points to trace the water surface profile. From this, the water depth, $h_{0}$, was defined by geometric projection.

Inlet specific flows were in the range of 0.05 to $0.20 \mathrm{~m}^{3} / \mathrm{s} / \mathrm{m}$. The inlet total flow was measured with an electromagnetic flowmeter Endress Häuser Promag 53W of $125 \mathrm{~mm}$ with an accuracy of $0.5 \%$. Tests were performed with five different longitudinal rack slopes. Further details of the model may be obtained in References [4,7].

The approaching flow is subcritical in all the cases at the beginning of the inlet channel. The flow reaches supercritical conditions at the beginning of the rack.

Scale models are traditionally used to design bottom intake systems. For instance, White et al. [5] used a 1:6 model for the design of bottom intakes at the Sai Kung peninsula in Hong Kong; Orth et al. [15] experimented with a 1:5 model for a bottom intake at the Grand Prix river in the Savoy region; Vargas [13] used a 1:10 model for an intake at the Macho river in Costa Rica; and Drobir [19] considered a 1:10 scale model at the Verpeil bottom intake in the power plant Kaunertal (Austria). Bottom intakes are usually designed to derive flows from 0.5 to $3.0 \mathrm{~m}^{3} / \mathrm{s} / \mathrm{m}[19,23]$. With those considerations, the laboratory model used would be considered to design prototypes with scales between 1:5 and 1:20.

\section{Results and Discussion}

The experimental campaign consisted of around 376 measurements of wetted rack length with five different racks considered. Once the wetted rack length had been experimentally measured, the mean discharge coefficient was calculated using Equation (1).

From an empirical point of view, the relations between different variables are sought. These variables are obtained from a dimensional analysis. From previous experiences in bottom intake 
systems [4-7], the main variables with an influence in the definition of the mean discharge coefficient $\overline{C_{q H}}$ and the wetted rack length are presented in:

$$
f\left(U_{0}, h_{0}, \mu, \sigma, \rho, g, \tan \theta, m, C_{q 0}, \overline{C_{q H}}\right)=0,
$$

where $U_{0}$ is the mean velocity at the beginning of the rack, calculated as the relation between the incoming flow and the flow depth at the beginning of the rack, $q / h_{0}, \mu$ the kinematic viscosity; $\rho$ the density, and $\sigma$ the surface tension of water. $\tan \theta$ expresses the longitudinal slope of the rack. $C_{q 0}$ is the discharge coefficient measured in static conditions whose values are presented in Figure 6:

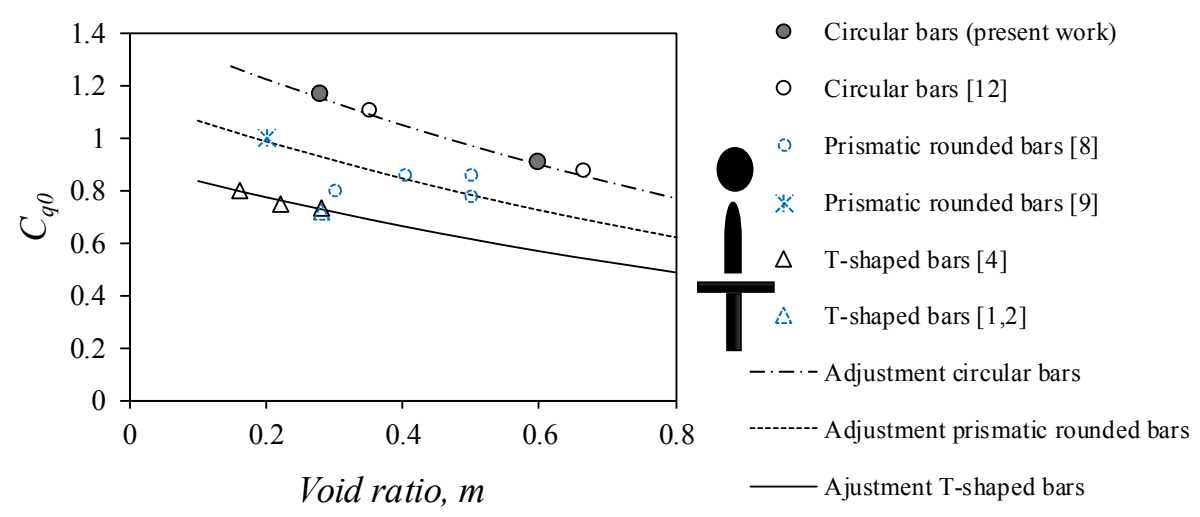

Figure 6. Static discharge coefficient measurements and proposed adjustments.

Previous adjustments proposed for the static discharge coefficient $[3,4]$ are presented in the following equations:

$$
\begin{gathered}
\text { Circular bars : } C_{q 0}=1.4287 e^{-0.771 m}, \\
\text { Prismatic bars : } C_{q 0}=1.15 e^{-0.771 m,} \\
\mathrm{~T} \text { - shaped bars : } C_{q 0}=0.901 e^{-0.771 m},
\end{gathered}
$$

These adjustments include new values measured in this work for racks made with circular bars. The additional values do not introduce modifications in the expressions (see Figure 6).

From Equation (2), 10 main variables are considered $(n=10)$. Considering the Buckingham's Theorem $\Pi$, a reduced number of dimensionless parameters can be found. There are $k=3$ independent variables (basic dimensions: mass, length and time), with which we can reduce the problem to $p=n-k=7$ dimensionless variables [36]. Selecting the independent variables $\rho, U_{0}, h_{0}$, the dimensionless parameters may be obtained as a function of the mean discharge coefficient:

$$
\overline{C_{q H}}=f\left(\frac{U_{0} h_{0}}{\mu / \rho}, \frac{U_{0}^{2} h_{0}}{\sigma / \rho}, \frac{U_{0}}{\sqrt{g h_{0}}}, \tan \theta, m, C_{q 0}\right),
$$

or:

$$
\overline{C_{q H}}=f\left(R_{e 0}, W_{e 0}, F_{r 0}, \tan \theta, m, C_{q 0}\right),
$$

where $R_{e 0}, W_{e 0}$, and $F_{r 0}$ are the Reynolds, Weber and Froude numbers, respectively. The sub-index 0 indicates that variables are calculated at the beginning of the rack.

Once the dimensionless variables have been obtained, their influence in the mean discharge coefficient may be analysed by Equation (7).

Considering empirical and inspectional analysis, a reduced expression of the mean discharge coefficient is presented in the following sections. 


\subsection{Flow Depth vs Incoming Flow}

From an inspectional point of view, the flow over bottom racks is considered a flow governed by gravitational forces or by Froude number $F_{r 0}$. From this dimensionless number, the flow depth at the beginning of the rack $h_{0}$, may be related with the incoming specific flow through:

$$
h_{0}=f\left(q^{2 / 3}\right)
$$

From an empirical point of view, Figures 7-11 present the values of flow depth at the beginning of the rack with the incoming flow for the five different racks tested, and distinguishing the five different longitudinal slopes. At these figures, the experimental values are overlapped with dashed lines that represent a potential curve fit. The ratio flow depth/incoming flow follows Equation (8), with a power of $2 / 3$.

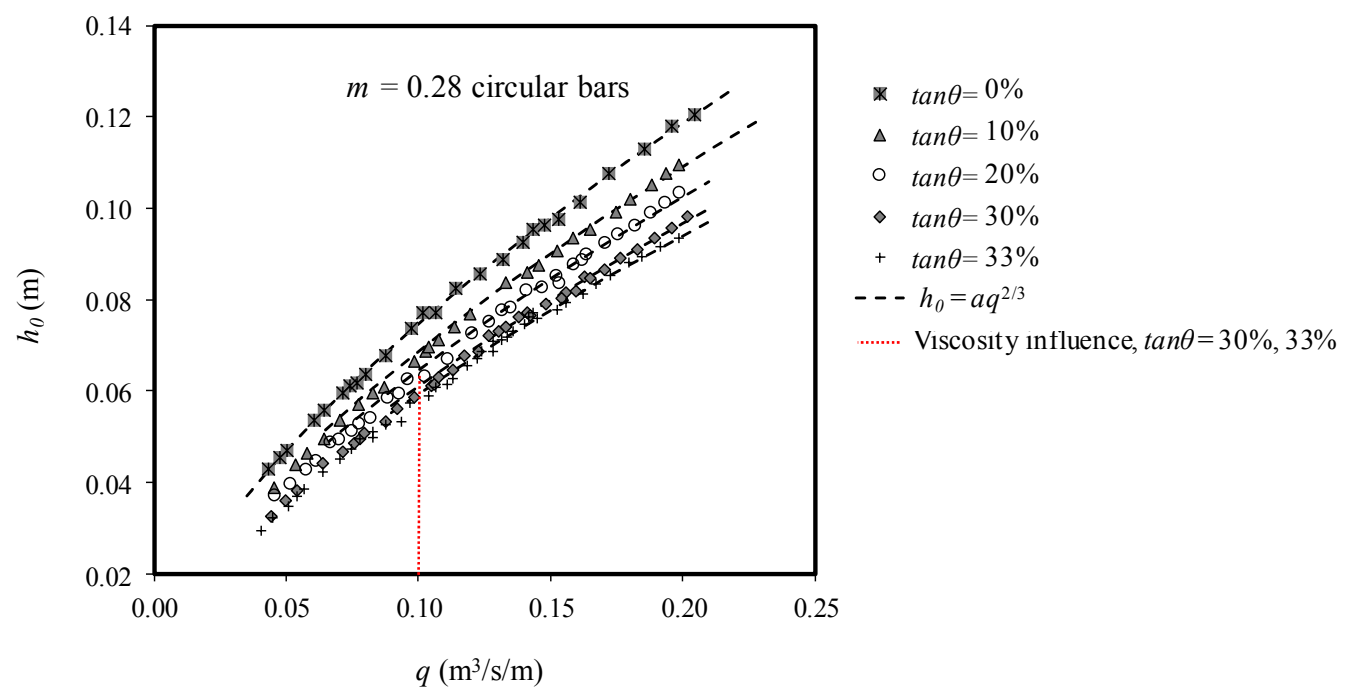

Figure 7. Flow depth at the beginning of the rack $h_{0}$ as a function of the incoming flow $q$. Circular bars with void ratio $m=0.28$.

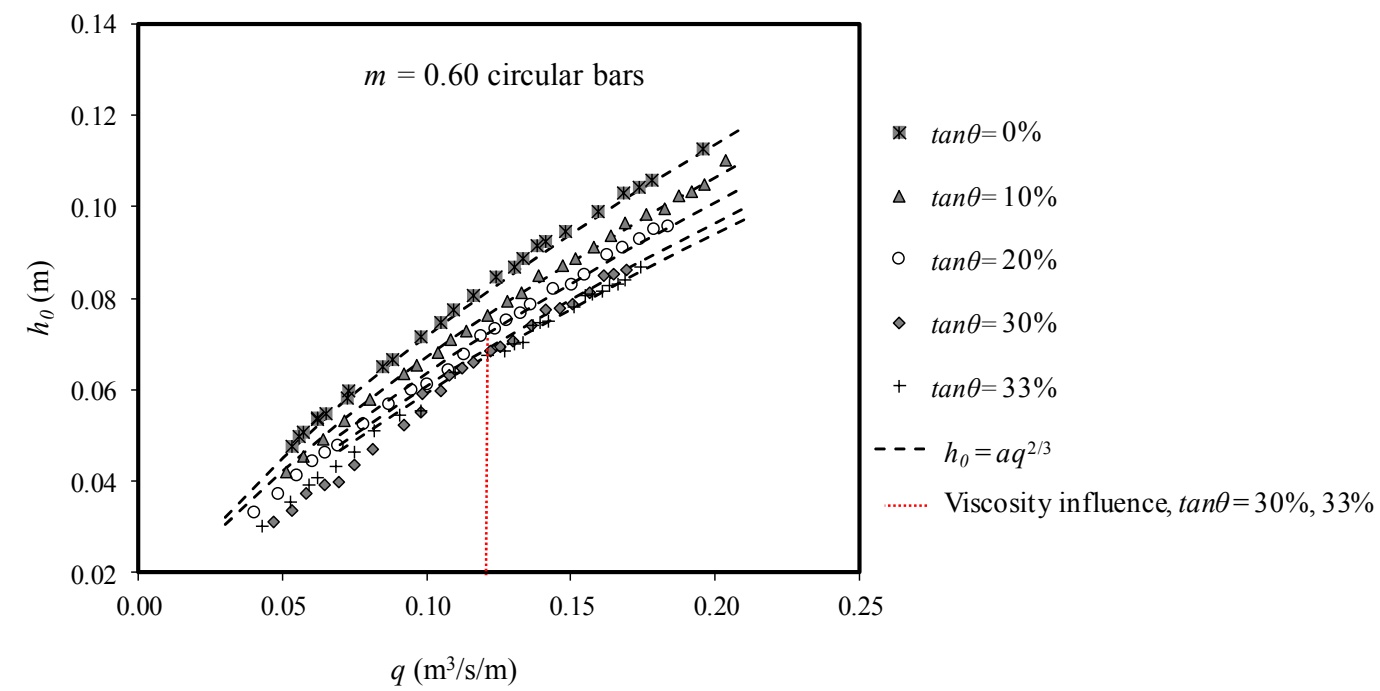

Figure 8. Flow depth at the beginning of the rack $h_{0}$ as a function of the incoming flow $q$. Circular bars with void ratio $m=0.60$. 


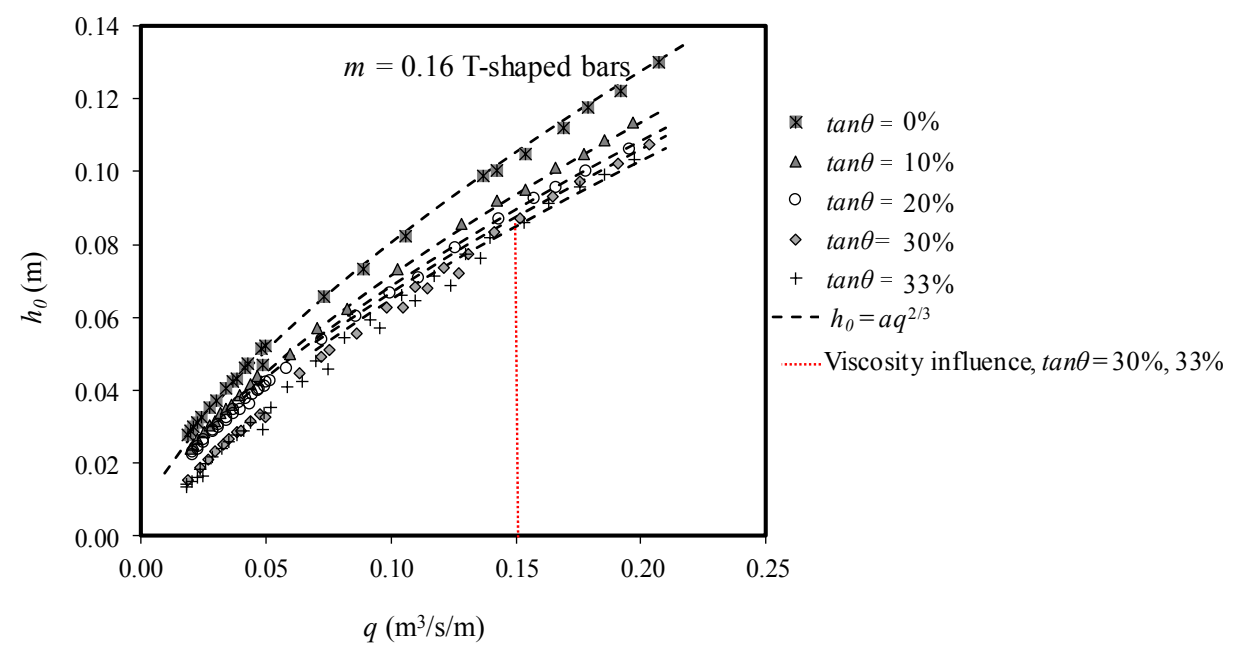

Figure 9. Flow depth at the beginning of the rack $h_{0}$ as a function of the incoming flow $q$. T-shape bars with void ratio $m=0.16$.

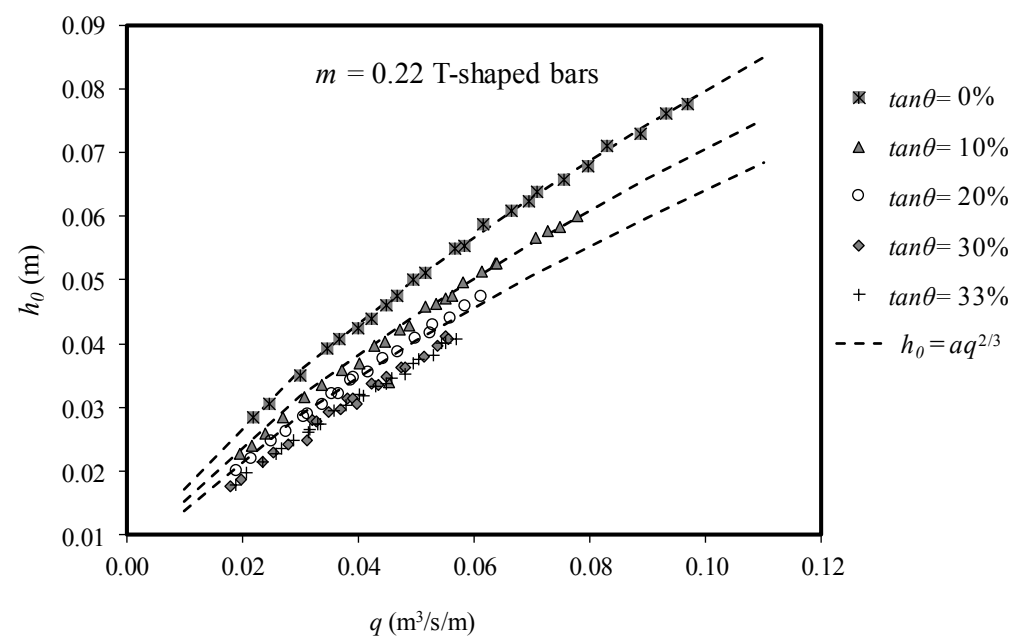

Figure 10. Flow depth at the beginning of the rack $h_{0}$ as a function of the incoming flow $q$. T-shape bars with void ratio $m=0.22$.

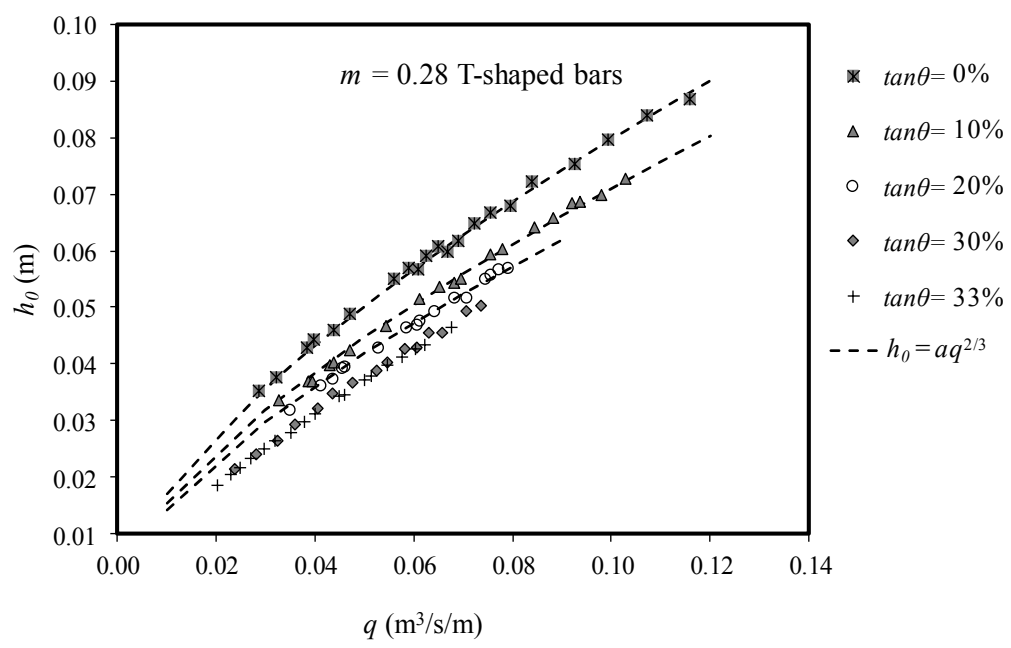

Figure 11. Flow depth at the beginning of the rack $h_{0}$ as a function of the incoming flow $q$. T-shape bars with void ratio $m=0.28$. 
In the horizontal slope case, the values of $h_{0}$ adjust to the power of the flow proposed in Equation (8) in all the range of the incoming flows considered in the present study. However, in the case of longitudinal slopes of $30 \%$ and $33 \%$, Equation (8) is not accomplished until values of incoming flow are larger than a specific value. For instance, $0.15 \mathrm{~m}^{3} / \mathrm{s} / \mathrm{m}$ in the rack of T-shaped bars and void ratio $m=0.16$. These lower limit incoming flows are shown in Table 2 .

Table 2. Viscosity influence in the flow depth at the beginning of the rack for $30 \%$ and $33 \%$ longitudinal slopes.

\begin{tabular}{cccc}
\hline Bar Type & Void Ratio, $\boldsymbol{m}$ & Longitudinal Slope & $\begin{array}{c}\text { Flow with Viscosity } \\
\text { Influence, for } \boldsymbol{q}=\mathbf{~ m}^{\mathbf{3}} \mathbf{/ s} / \mathbf{m}\end{array}$ \\
\hline Circular & 0.28 & & $<0.10$ \\
Circular & 0.60 & $30 \%, 33 \%$ & $<0.12$ \\
T-shaped & 0.16 & & $<0.15$ \\
\hline
\end{tabular}

In this sense, the empirical influence of the surface tension and the viscous forces are observed in the flow depth at the beginning of the rack in high slope cases. Table 2 includes a summary of the range of flows that do not accomplish Equation (8) related to the longitudinal slope for each rack. In the case of T-shaped flat bars with a void ratio $m=0.22$ and 0.28 , the flow depth measurements were not extended as long as necessary to avoid viscosity influence, due to the dimensions of the laboratory infrastructure.

The Froude number, $F_{r 0}$, was also compared with the measured wetted rack length, $L$, in Figures 12-14. In low wetted rack lengths and high longitudinal rack slopes, the Froude numbers reach higher values that do not follow the almost horizontal trend observed for larger flows. For instance, in the rack with circular bars, a void ratio $m=0.60$, and slopes of $30 \%$ and $33 \%$, all the cases of wetted rack length larger than $0.40 \mathrm{~m}$ adjust to a horizontal trend. In low wetted rack lengths and high longitudinal slopes cases, the values of Froude number calculated at the beginning of the rack $F_{r 0}$ may be considered affected by viscosity influence. These effects seem to be more important for larger longitudinal slopes. Surface tension and viscous effects are not negligible with water depths lower than $0.05 \mathrm{~m}[35,37]$. Those depths were found for low incoming flows and slopes of $30 \%$ and $33 \%$.

Table 3 includes a summary of the range of wetted rack lengths where it is considered that viscosity influence appears. The flow depths, $h_{0}$, associated to these cases are in the range of $0.032 \mathrm{~m}$ to $0.050 \mathrm{~m}$. For water depth values smaller than $0.050 \mathrm{~m}$, surface tension effects may not be neglected as stated by Rouse [34], Heller [35] and Chanson [37]. The results are in agreement with those presented in Table 2.
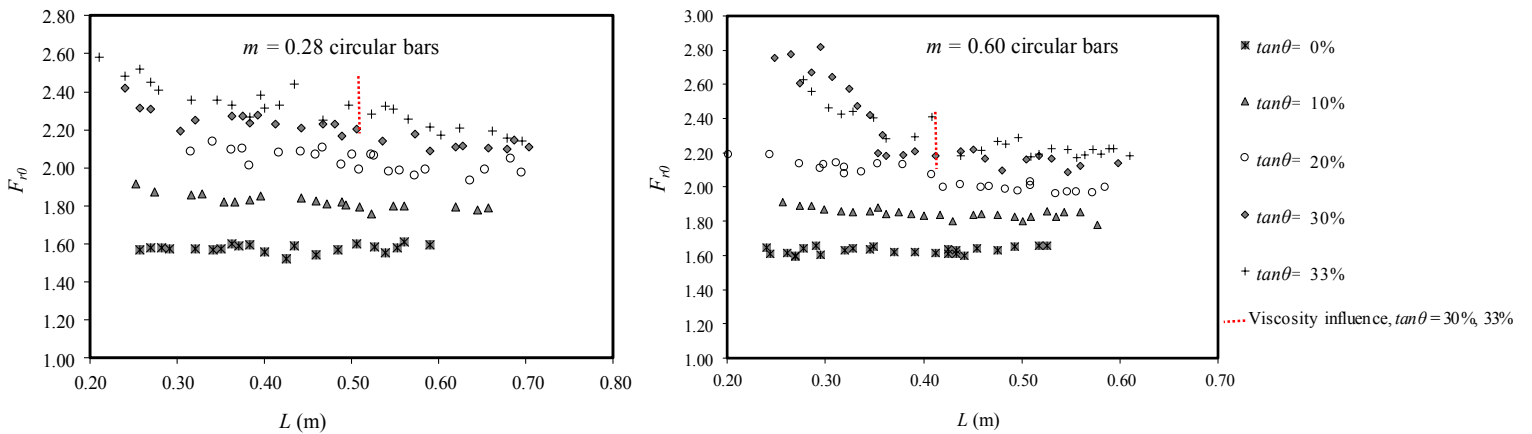

Figure 12. Froude number at the beginning of the rack $F_{r 0}$ as a function of the wetted rack length for circular bars with void ratios $m=0.28$ and 0.60 . 

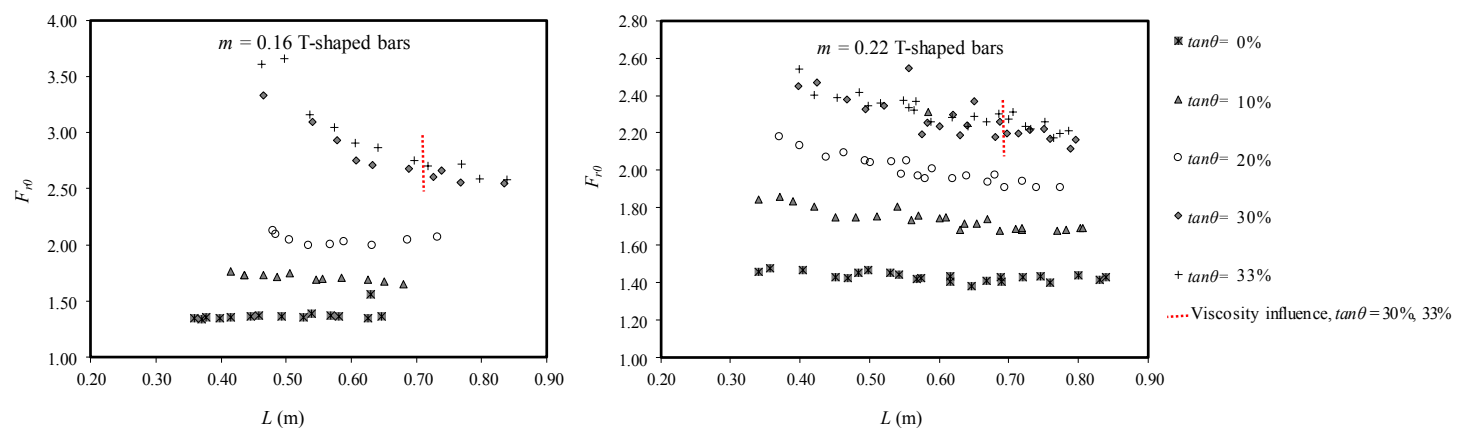

Figure 13. Froude number at the beginning of the rack $F_{r 0}$ as a function of the wetted rack length for T-shaped flat bars with void ratios $m=0.16$ and 0.22 .

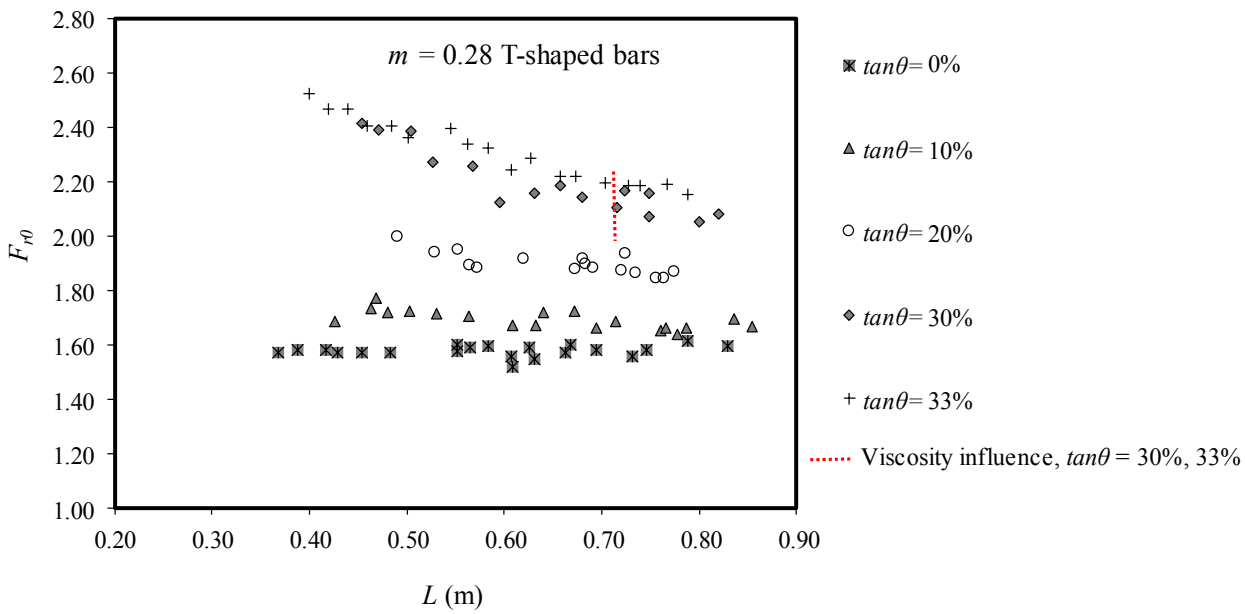

Figure 14. Froude number at the beginning of the rack $F_{r 0}$ as a function of the wetted rack length $L$, for T-shaped flat bars with void ratio $m=0.28$.

Table 3. Viscosity influence in the flow depth at the beginning of the rack in the case of 30 and $33 \%$ longitudinal slopes.

\begin{tabular}{cccccc}
\hline Bar Type & Void Ratio, $\boldsymbol{m}$ & $\begin{array}{c}\text { Longitudinal } \\
\text { Slope }\end{array}$ & $\begin{array}{c}\text { Length with Viscosity } \\
\text { Influence, }(\mathbf{m})\end{array}$ & $\begin{array}{c}\text { Flow Depth, } \\
\boldsymbol{h}_{\mathbf{0}}(\mathbf{m})\end{array}$ & $\boldsymbol{R}_{\boldsymbol{e} \mathbf{0}}$ \\
\hline Circular & 0.28 & & $<0.50$ & $<0.050$ & $<103,080$ \\
Circular & 0.60 & & $<0.40$ & $<0.054$ & $<111,313$ \\
T-shaped & 0.16 & $30 \%, 33 \%$ & $<0.70$ & $<0.032$ & $<35,303$ \\
T-shaped & 0.22 & & $<0.70$ & $<0.034$ & $<43,131$ \\
T-shaped & 0.28 & & $<0.70$ & $<0.038$ & $<52,777$ \\
\hline
\end{tabular}

\subsection{Reynolds Number $R_{e 0}$ vs. Wetted Rack Length $L$}

Brunella et al. [12] proposed an expression to calculate the critical Reynolds number in bottom intake systems. Those authors estimated that there are no scaling effects when this value is bigger than 250,000 , which corresponds with specific flows greater than $75 \mathrm{l} / \mathrm{s} / \mathrm{m}$ in the laboratory model used. In the previous section, Table 3 presents values of Reynolds number, $R_{e 0}$, calculated from flow depth measured at the beginning of the rack, $h_{0}$, according to Equations (6) and (7) from which viscous effects are observed in function of longitudinal rack slopes.

Figures 15-17 compare the Reynolds numbers obtained at the beginning of the rack with their corresponding wetted rack lengths. Tests include the five different racks, distinguishing the five different longitudinal slopes. The measured Reynolds number, $R_{e 0}$, was in the range of 18,200 to 
213,000 in the case of circular bars and 16,400 to 105,000 for the T-shaped bars. Experimental values overlapped with dashed lines that represent a potential curve fit, relating $R_{e 0}$ with $L$ using a potential function:

$$
R_{e 0}=f\left(L^{\text {power }}\right),
$$

Racks with voids ratios of $m=0.16,0.22$ and 0.28 follow the power of 1.62 , irrespective of the bar type. However, $m=0.60$ follows the power of 2.14. According to the results, the spacing between the bars is the value that distinguishes the power ratio between $R_{e 0}$ and $L$. As seen in Table 1 , the separation between bars of $m=0.60\left(b_{1}=0.045 \mathrm{~m}\right)$ is almost four times longer than for $m=0.28\left(b_{1}=0.0117 \mathrm{~m}\right)$.
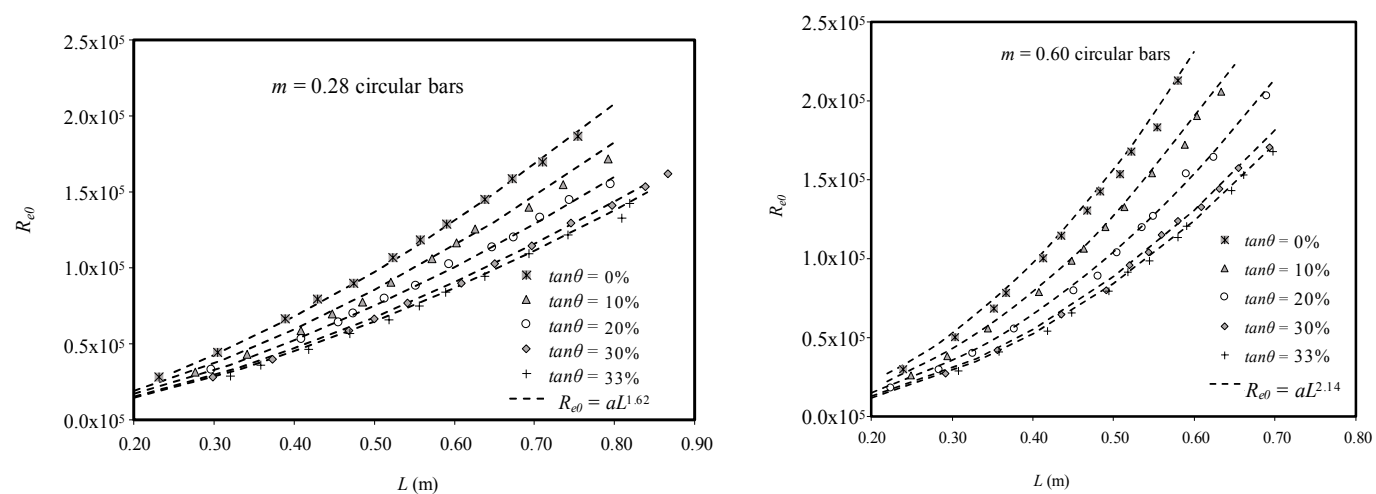

Figure 15. Reynolds number at the beginning of the rack $R_{e 0}$ as a function of the wetted rack length $L$, for circular bars with void ratio $m=0.28$ and 0.60 .
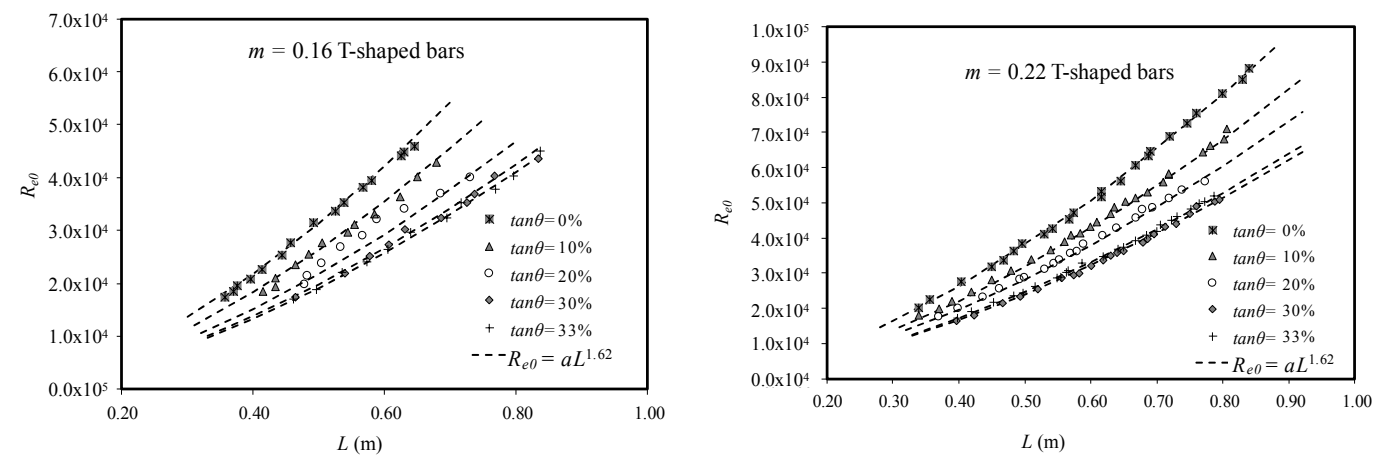

Figure 16. Reynolds number at the beginning of the rack $R_{e 0}$ as a function of the wetted rack length $L$, for T-shaped flat bars with void ratio $m=0.16$ and 0.22 .

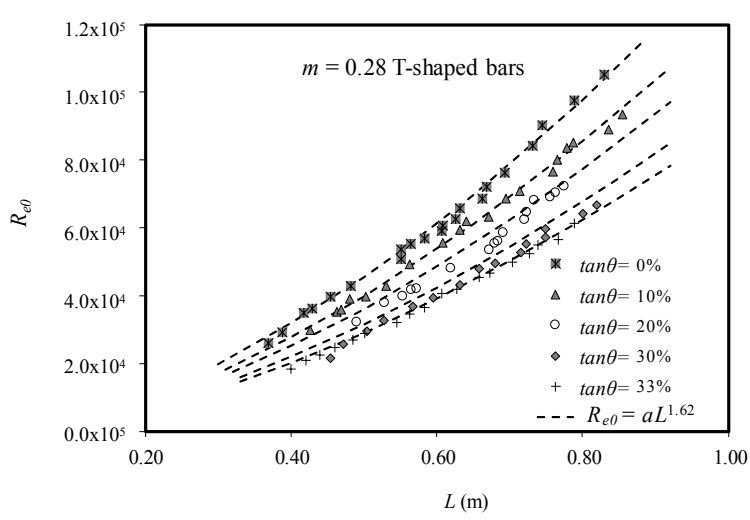

Figure 17. Reynolds number at the beginning of the rack $R_{e 0}$ as a function of the wetted rack length $L$, for T-shaped flat bars with void ratio $m=0.28$. 


\subsection{Weber Number $W_{e 0}$ vs. Wetted Rack Length $L$}

Figures 18-20 show the relation of the Weber numbers measured at the beginning of the rack with their wetted rack lengths. Graphs include the five racks, distinguishing the five longitudinal slopes. The weber number, $W_{e 0}$, was in the range of 251 to 5930 in the case of circular bars and 182 to 2120 for the T-shaped bars. Dashed lines represent a potential curve that relates $W_{e 0}$ with $L$. Results with voids ratios of $m=0.16,0.22$ and 0.28 follow the power of 2.16, irrespective of the bar type. Data of $m=0.60$ follows the power of 2.86. In this sense, the spacing between the bars is the value that distinguishes the power ratio between $W_{e 0}$ and $L$.
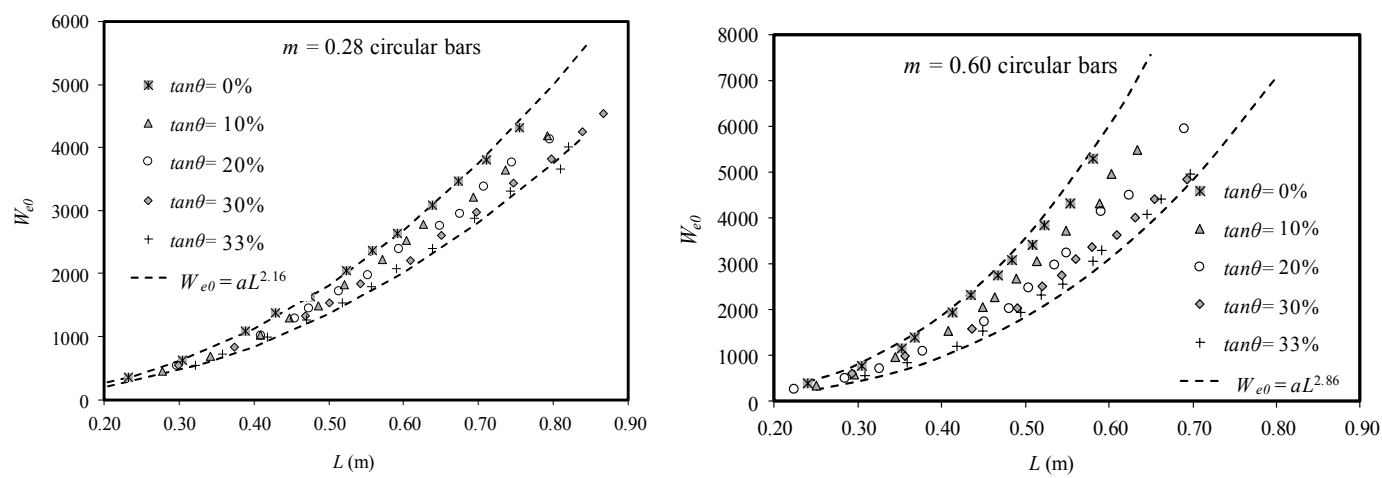

Figure 18. Weber number at the beginning of the rack $W_{e 0}$ as a function of the wetted rack length $L$, for circular bars with void ratio $m=0.28$ and 0.60 .
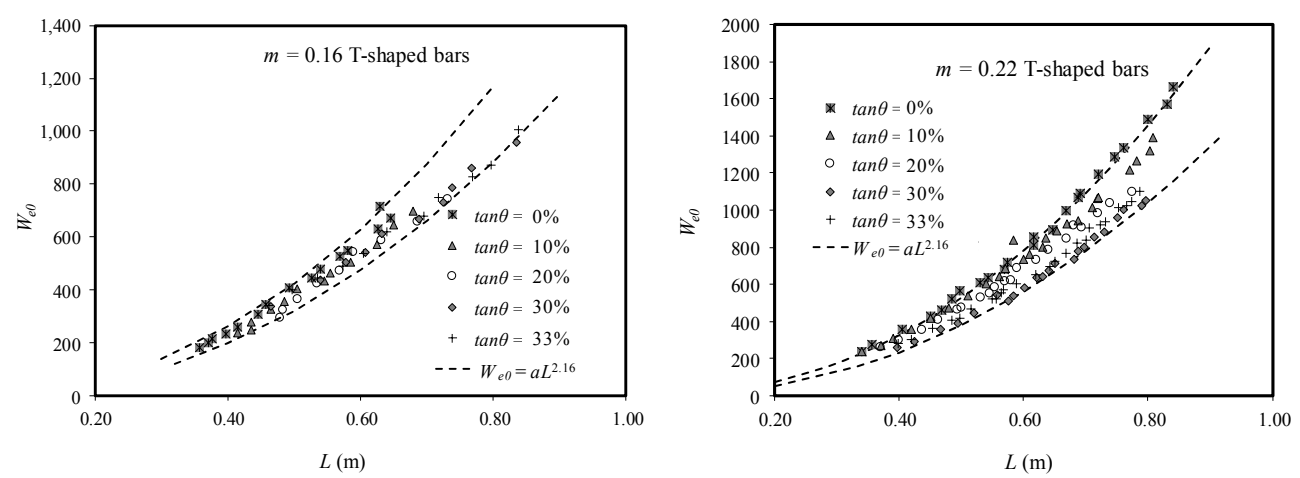

Figure 19. Weber number at the beginning of the rack $W_{e 0}$ as a function of the wetted rack length $L$, for T-shaped flat bars with void ratio $m=0.16$ and 0.22 .

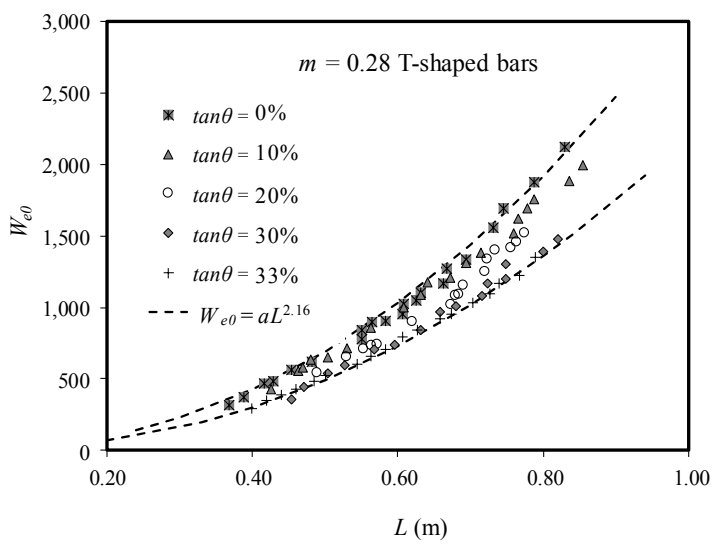

Figure 20. Weber number at the beginning of the rack $W_{e 0}$ as a function of the wetted rack length $L$, for T-shaped flat bars with void ratio $m=0.28$. 


\subsection{Mean Discharge Coefficient $\overline{C_{q H}}$ vs. Incoming Flow $q$}

From the experimental measurements of wetted rack length and using Equation (1), the mean discharge coefficient $\overline{C_{q H}}$ may be calculated. An adjustment as a function of the bar type and spacing between bars may be considered:

$$
\overline{C_{q H}}=\frac{a m C_{q 0}}{(1+\tan \theta)} q^{b},
$$

where constants $a$ and $b$ have been obtained for each void ratio and bar type. Those are the parameters collected in Table 4.

Table 4. Constants of Equation (10) for the adjustment of the mean discharge coefficient $\overline{C_{q H}}$.

\begin{tabular}{cccc}
\hline Bar Type & $\boldsymbol{m}$ & $\boldsymbol{a}$ & $\boldsymbol{b}$ \\
\hline $\mathrm{T}$ & 0.16 & 3.3 & 0.05 \\
$\mathrm{~T}$ & 0.22 & 2.1 & 0.05 \\
$\mathrm{~T}$ & 0.28 & 1.5 & 0.05 \\
$\mathrm{O}$ & 0.28 & 1.45 & 0.05 \\
$\mathrm{O}$ & 0.60 & 0.70 & 0.20 \\
\hline
\end{tabular}

Figures 21-25 show the values of the mean discharge coefficient calculated and adjusted with Equation (10). According to Equation (10), the mean discharge coefficient is a function of the flow with a power defined by the parameter $b(0.05$ for void ratios of $m=0.16,0.22$ and $0.28 ; 0.2$ for void ratio of $m=0.60)$. An important influence of the spacing between bars is observed, as appeared in previous sections.

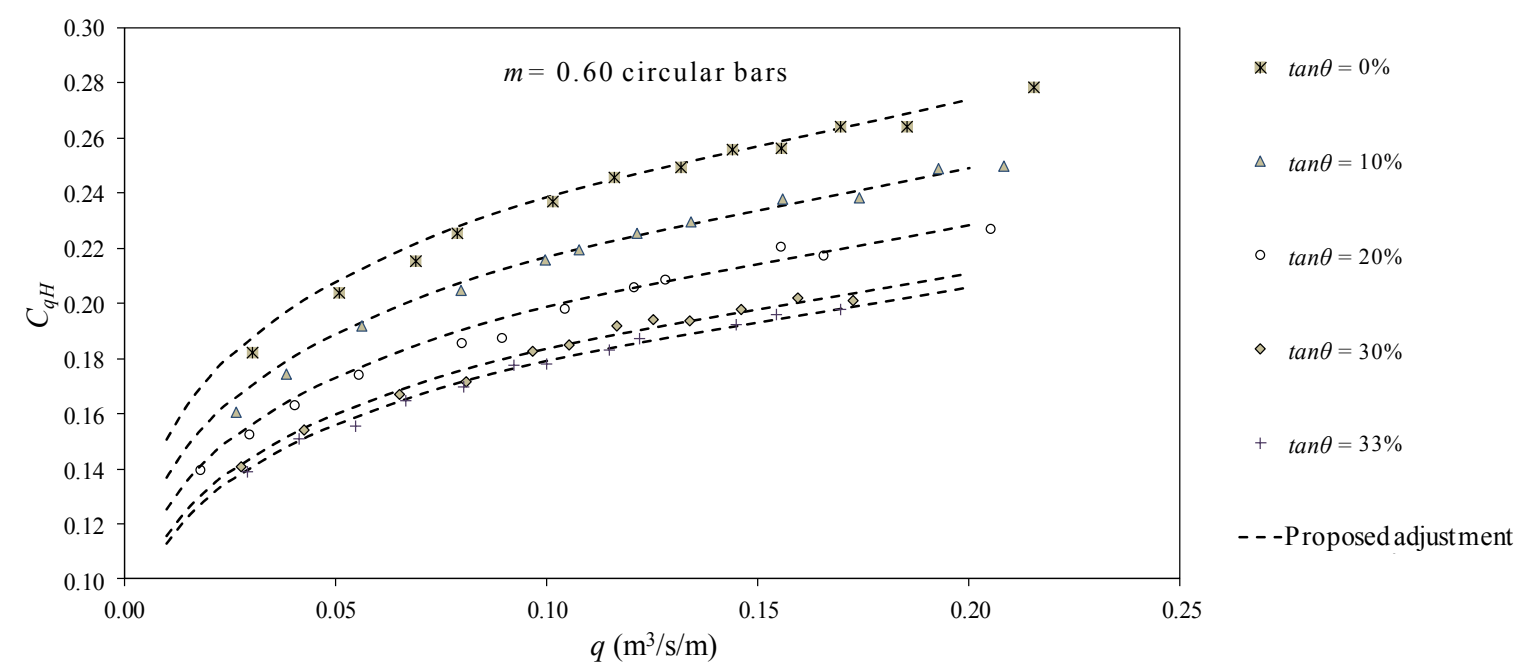

Figure 21. Mean discharge coefficient $\overline{C_{q H}}$ as a function of the incoming flow $q$, for circular bars with void ratio $m=0.60$. 


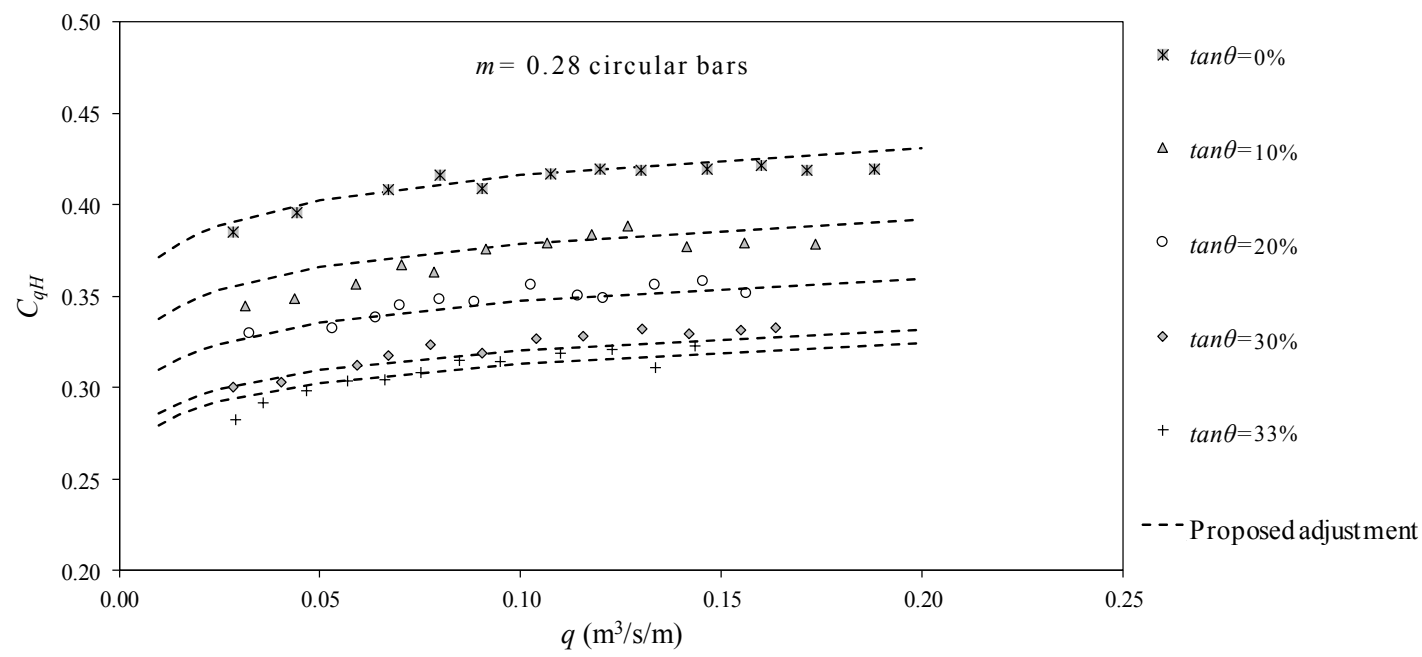

Figure 22. Mean discharge coefficient $\overline{C_{q H}}$ as a function of the incoming flow $q$, for circular bars with void ratio $m=0.28$.

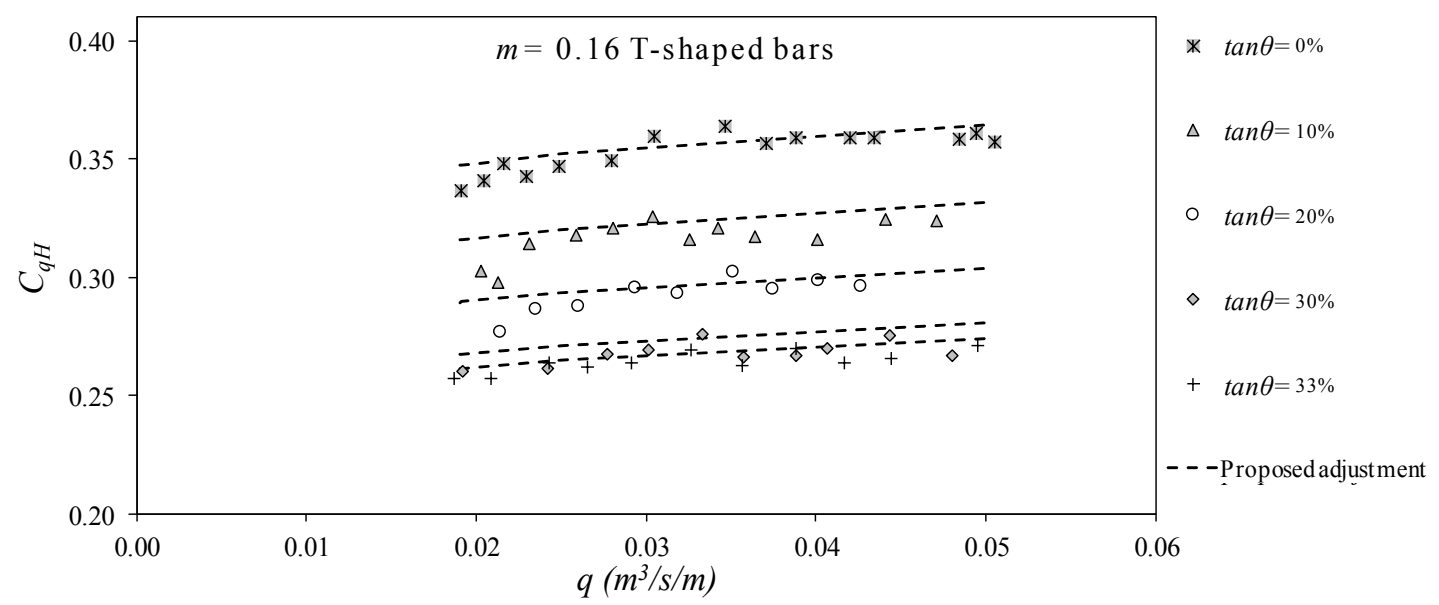

Figure 23. Mean discharge coefficient $\overline{C_{q H}}$ as a function of the incoming flow $q$, for T-shaped flat bars with void ratio $m=0.16$.

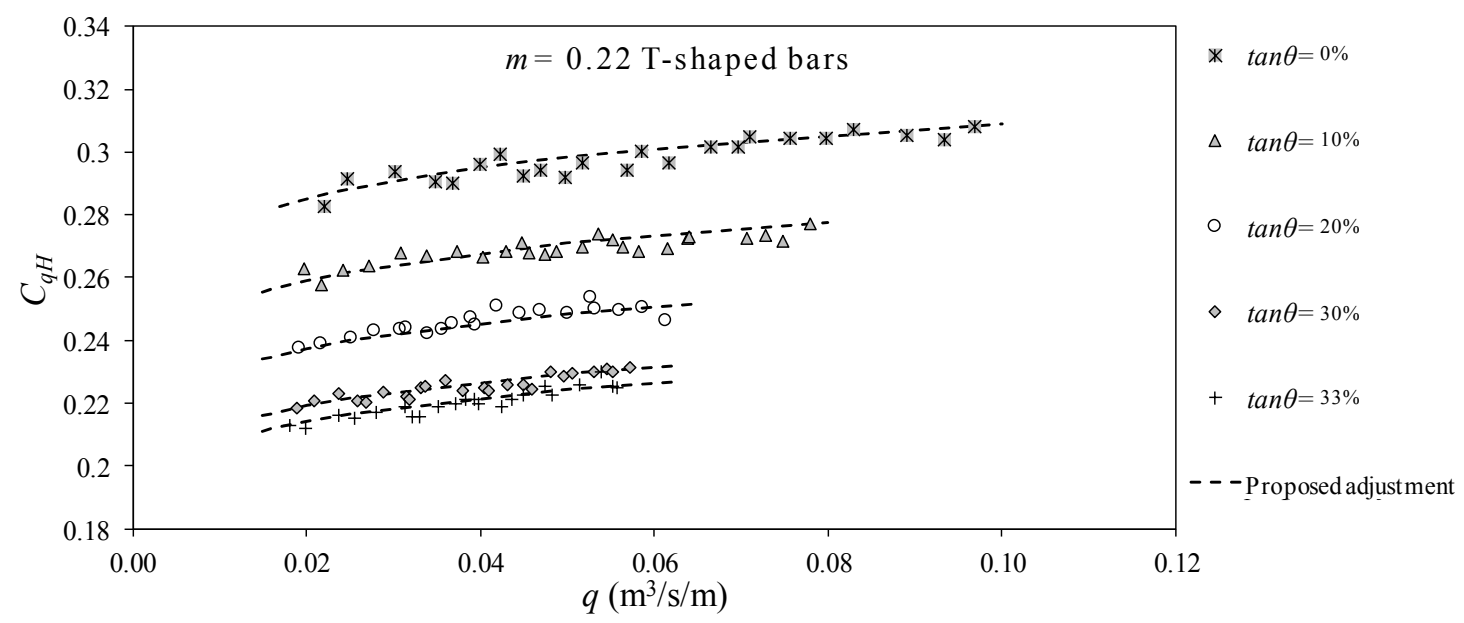

Figure 24. Mean discharge coefficient $\overline{C_{q H}}$ as a function of the incoming flow $q$, for T-shaped flat bars with void ratio $m=0.22$. 


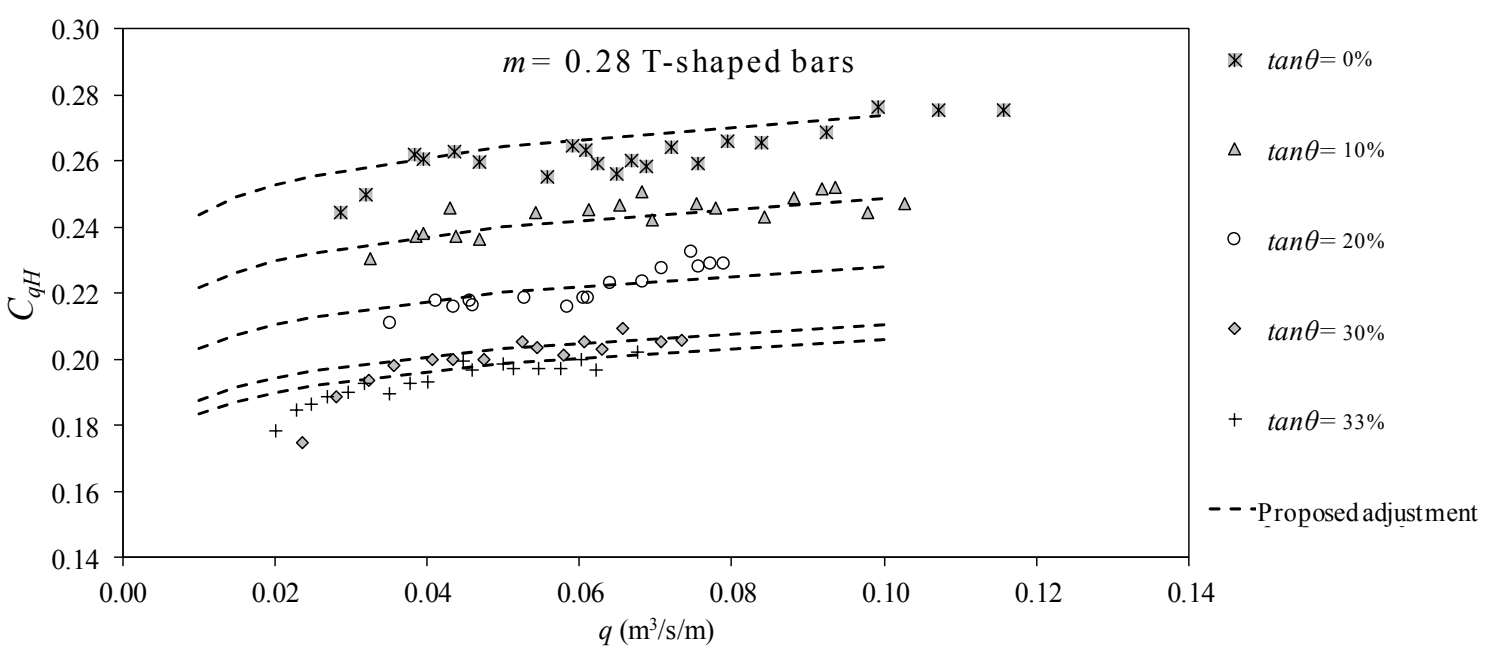

Figure 25. Mean discharge coefficient $\overline{C_{q H}}$ as a function of the incoming flow $q$, for T-shaped flat bars with void ratio $m=0.28$.

An index of goodness of the adjustment IG may be considered. This parameter represents the sample standard deviation of the differences between measured and calculated values:

$$
I G=\sqrt{\frac{1}{n} \sum_{i}^{n}\left(L_{\text {measured_i } i}-L_{\text {calculated_i } i}\right)^{2}}
$$

where $I G$ is the root mean square deviation proposed as an index of the goodness of the fit between the measured and calculated, $L_{\text {measured } \_i}$ is the wetted rack length measured in the laboratory, $L_{\text {calculated } \_i}$ is the wetted length calculated with Equations (1) and (10), and $n$ is the number of measured events. The values of $I G$ for each rack and void ratio are shown in Table 5. Good agreement was obtained in all the cases, with values lower than $1.17 \times 10^{-2} \mathrm{~m}$.

Table 5. Index of goodness of the fit between measured and calculated values.

\begin{tabular}{ccccccc}
\hline & & \multicolumn{5}{c}{ Slope (\%) } \\
\cline { 3 - 7 } Bar Type & Void Ratio $\boldsymbol{m}(-)$ & $\mathbf{0}$ & $\mathbf{1 0}$ & $\mathbf{2 0}$ & $\mathbf{3 0}$ & $\mathbf{3 3}$ \\
& & & & $\mathbf{I G} \mathbf{( m )}$ & \\
\hline $\mathrm{T}$ & 0.16 & $5.609 \times 10^{-3}$ & $1.083 \times 10^{-2}$ & $8.105 \times 10^{-3}$ & $1.477 \times 10^{-2}$ & $7.635 \times 10^{-3}$ \\
$\mathrm{~T}$ & 0.22 & $1.190 \times 10^{-2}$ & $1.258 \times 10^{-2}$ & $6.574 \times 10^{-3}$ & $2.391 \times 10^{-2}$ & $5.979 \times 10^{-3}$ \\
$\mathrm{~T}$ & 0.28 & $1.252 \times 10^{-2}$ & $1.036 \times 10^{-2}$ & $1.193 \times 10^{-2}$ & $1.452 \times 10^{-2}$ & $9.113 \times 10^{-3}$ \\
$\mathrm{O}$ & 0.28 & $8.374 \times 10^{-3}$ & $1.214 \times 10^{-2}$ & $6.386 \times 10^{-3}$ & $8.891 \times 10^{-3}$ & $8.686 \times 10^{-3}$ \\
$\mathrm{O}$ & 0.60 & $6.325 \times 10^{-3}$ & $4.885 \times 10^{-3}$ & $8.436 \times 10^{-3}$ & $6.016 \times 10^{-3}$ & $4.261 \times 10^{-3}$ \\
\hline
\end{tabular}

The experimental uncertainty is around $2 \mathrm{~mm}$ for the water depth accuracy and around $5 \mathrm{~mm}$ for the wetted rack length.

\subsection{Inspectional Analysis}

From an inspectional analysis, the orifice equation (Equation (1)) may be chosen to adjust and represent the flow collected in a bottom intake rack. Hence, the ratio between the wetted rack length $L$ and the incoming flow rate $q$ may be obtained as:

$$
L=\frac{q}{\overline{C_{q H}} m \sqrt{2 g H_{\min }}},
$$


Starting from this equation, each variable may be expressed as a power function of the incoming flow $q$.

By definition, $H_{\min }$ is a function of $q^{2 / 3}$ because it is obtained when the Froude number equals the unity, and there is critical depth.

From Section 3.4, the mean discharge coefficient $\overline{C_{q H}}$, is a function of $q^{0.05}$ (if void ratio is $m=0.16$, 0.22 and 0.28 ) or $q^{0.2}$ (if $m=0.60$ ). At this point, Equation (11) can be expressed as:

$$
\begin{gathered}
\text { if } m=0.16,0.22 \text { and } 0.28 \rightarrow L=f\left(\frac{q}{q^{0.05} q^{1 / 3}}\right)=f\left(q^{0.62}\right), \\
\quad \text { if } m=0.60 \rightarrow L=f\left(\frac{q}{q^{0.2} q^{1 / 3}}\right)=f\left(q^{0.46}\right),
\end{gathered}
$$

Expressions of Equations (15) and (16) can also be linked with empirical observations (see Figures 15-17) between the wetted rack length and the Reynolds number $R_{e 0}$ as:

$$
\begin{gathered}
\text { if } m=0.16,0.22 \text { and } 0.28 \rightarrow R_{e 0}=\frac{U_{0} h_{0}}{\mu / \rho}=\frac{\left(q / h_{0}\right) * h_{0}}{\mu / \rho}=\frac{q}{\mu / \rho}=f\left(L^{1 / 0.62}\right)=f\left(L^{1.62}\right), \\
\text { if } m=0.60 \rightarrow R_{e 0}=\frac{U_{0} h_{0}}{\mu / \rho}=\frac{\left(q / h_{0}\right) * h_{0}}{\mu / \rho}=\frac{q}{\mu / \rho}=f\left(L^{1 / 0.46}\right)=f\left(L^{2.14}\right),
\end{gathered}
$$

Hence, from inspectional analysis, the relations found between $L$ and $R_{e 0}$ in Figures 15-17 have been confirmed.

In the same way, the expressions of Equations (17) and (18) can also be linked with the empirical observations between the wetted rack length and the Weber number $W_{e 0}$ (see Section 3.3).

$$
\begin{gathered}
\text { If } m=0.16,0.22 \text { and } 0.28 \rightarrow W_{e 0}=\frac{U_{0}^{2} h_{0}}{\sigma / \rho}=\frac{q^{2} / h_{0}}{\sigma / \rho}=f\left(q^{2} / q^{2 / 3}\right)=f\left(L^{2.16}\right), \\
\text { If } m=0.60 \rightarrow W_{e 0}=\frac{U_{0}^{2} h_{0}}{\sigma / \rho}=\frac{q^{2} / h_{0}}{\sigma / \rho}=f\left(q^{2} / q^{2 / 3}\right)=f\left(L^{2.86}\right),
\end{gathered}
$$

In Equations (17) and (18), it has also been considered that the flow depth $h_{0}$ and the incoming flow $q$ are related by the power of $2 / 3$, in the range where no viscosity influence is considered.

\subsection{Comparison of Results with Field Measurements}

Drobir [19] obtained field measurements in a Tyrolean weir of the bottom intake system of Verpeil, at the Kaunertal power plant. From field measurements, Drobir [19] proposed an envelope of wetted rack length called $L_{2}$. Measurements were taken in a bottom intake with the void ratio of $m=0.60$ and a longitudinal slope of $20 \%$.

For the same case, in Figure 26, the wetted rack length has been obtained from Equation (12) using the mean discharge coefficient proposed in Equation (10) for $m=0.60$ and $20 \%$ of slope. Lengths are dimensionless with the critical depth and are represented for a broad range of flows. The length obtained with Equation (12) shows good agreement with the field measurements. The lengths calculated are lower than those proposed by the $L_{2}$ envelope of Drobir [19]. 


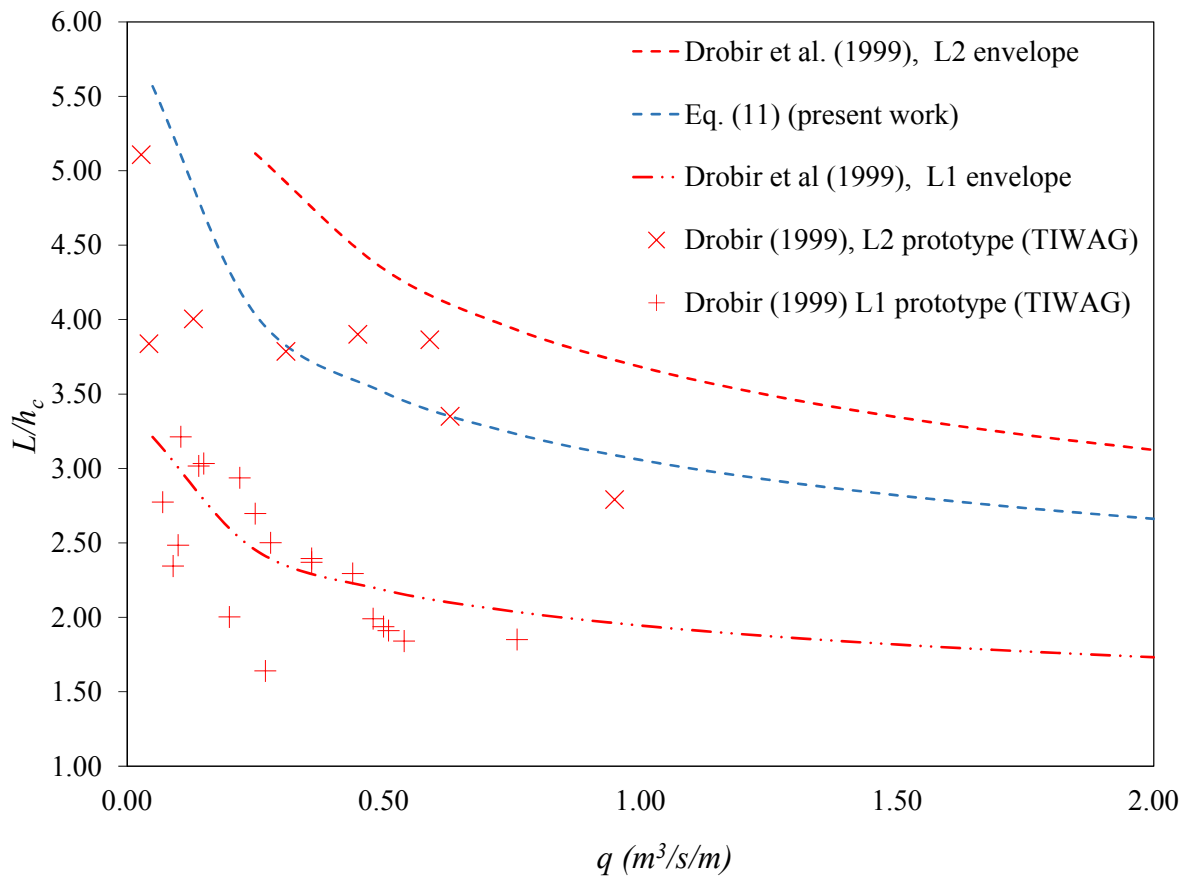

Figure 26. Comparison of adjusted wetted rack lengths $L, L_{1}$ and $L_{2}$ envelopes dimensionless with critical depth, as a function of the incoming flow for circular bars with $m=0.60$ and longitudinal slope of $20 \%$.

The index of goodness of the adjustment, IG, may be calculated between the predicted values using Equation (11) and the laboratory measurements, obtaining $I G=0.09$. This value of $I G$ represents a $10 \%$ of difference with the mean of the lengths measured in the field installation. As the field number of values is limited to seven, a difference of $10 \%$ may be considered acceptable.

\section{Conclusions}

In the design of bottom racks used in stepped streams to catch water, the discharge coefficient and the wetted length of the racks are considered key factors. Due to the complexity of flow over bottom racks, experimental works have always been needed. Empirical, dimensional and inspectional analyses are important tools that can help to reduce the variables and to select those parameters that have more influence on the phenomenon. Their analysis can also allow the identification of viscosity and surface tension influence in different conditions.

This work includes a broad experimental campaign in which the wetted rack length is measured for different incoming flows at rack slopes, with two types of bars.

From experimental works the relation between the flow depth at the beginning of the rack, $h_{0}$, and the incoming flow, $q$, has also been studied; this enables the effect of the viscosity forces for flows smaller than $0.14 \mathrm{~m}^{3} / \mathrm{s} / \mathrm{m}$ and for longitudinal slopes of 30 and $33 \%$ to be identified. Similar conclusions have been obtained with the Froude number at the beginning of the rack.

Empirical and inspectional analyses have allowed us to check the relation between the wetted rack length $L$, and the incoming flow $q$ in two different ways, obtaining potential functions. Besides this, empirical relations between the wetted rack length $L$, and non-dimensional numbers (Reynolds and Weber) have been analysed. Finally, with inspectional analysis, a relation of the mean discharge coefficient with the incoming flow has been proposed in Equation (10).

The separation between bars, $b_{1}$, influences the relations when the void ratio changes from 0.28 to 0.60 .

To summarize, from empirical, dimensional and inspectional analyses, the wetted rack length can be defined as a function only of the incoming flow through a potential function whose power has 
been defined. This single variable can also be the Reynolds number or the Weber number, which are usually considered variables of influence due to the decrease of the flow along the rack in this spatially varied flow.

Author Contributions: J.T.G. carried out the laboratory measurements, the data processing and analysis, and participated in the writing. L.G.C. carried out the analysis and application of the methodology, analyzed the results, and participated in the writing. J.M.C. carried out the data analysis, and participated in the writing. P.L.H. carried out the laboratory measurements and the data processing. All four authors reviewed and contributed to the final manuscript.

Funding: This research was funded by Seneca Foundation of Región de Murcia (Spain), grant number 19490/PI/14.

Acknowledgments: The authors are grateful for the financial support received from the Seneca Foundation of Región de Murcia (Spain) through the project "Optimización de los sistemas de captación de fondo para zonas semiáridas y caudales con alto contenido de sedimentos. Definición de los parámetros de diseño". Reference: 19490/PI/14.

Conflicts of Interest: The authors declare no conflict of interest.

\section{Notation}

\begin{tabular}{|c|c|}
\hline$a, b$ & $\begin{array}{l}\text { constant of adjustment depending on the shape of bars and the space between them in } \\
\text { Equation (10) }\end{array}$ \\
\hline$b_{1}$ & space between bars \\
\hline$b_{w}$ & bar width \\
\hline$\overline{C_{q H}}$ & mean discharge coefficient for energy head \\
\hline$C_{q h}$ & discharge coefficient for flow depth \\
\hline$C_{q 0}$ & static discharge coefficient \\
\hline$g$ & gravitational acceleration \\
\hline$H$ & energy head along the rack referred to the rack plane \\
\hline$H_{0}$ & energy head at the beginning of the rack referred to the rack plane \\
\hline$H_{\min }$ & $\begin{array}{l}\text { minimum energy head obtained when the Froude number equals the unity, and there is } \\
\text { critical depth }\end{array}$ \\
\hline$h_{c}$ & critical depth \\
\hline$h_{0}$ & flow depth at the beginning of the rack \\
\hline IG & $\begin{array}{l}\text { root mean square deviation proposed as an index of goodness of the fit between measured } \\
\text { and calculated wetted length }\end{array}$ \\
\hline$L_{\text {measured_i }}$ & is the wetted rack length measured in the laboratory $(\mathrm{m})$ as used in the $I G$ index \\
\hline$L_{\text {calculated_i }}$ & is the wetted length calculated with Equations (1) and (10) as used in the IG index \\
\hline$L$ & wetted rack length \\
\hline$L_{1}$ & envelope of the maximum wetted length over the bar \\
\hline$L_{2}$ & wetted length in the slit \\
\hline$m$ & void ratio \\
\hline$n$ & is the number of measured events \\
\hline$q_{1}$ & specific approaching flow \\
\hline$U$ & mean velocity \\
\hline$U_{0}$ & mean velocity at the beginning of the rack \\
\hline$\mu$ & kinematic viscosity of water \\
\hline$\rho$ & density of water \\
\hline$\sigma$ & surface tension of water \\
\hline$\theta$ & angle of the rack plane with the horizontal \\
\hline$F_{r_{0}}$ & Froude number calculated at the beginning of the rack \\
\hline$W_{e 0}$ & Weber number calculated at the beginning of the rack \\
\hline$R_{e 0}$ & Reynolds number calculated at the beginning of the rack \\
\hline
\end{tabular}




\section{References}

1. Noseda, G. Correnti permanenti con portata progressivamente decrescente, defluenti su griglie di fondo. L'Energia Elettr. 1956, 33, 41-51. (In Italian)

2. Noseda, G. Correnti permanenti con portata progressivamente decrescente, defluenti su griglie di fondo. L'Energia Elettr. 1956, 33, 565-588. (In Italian)

3. Castillo, L.G.; García, J.T.; Carrillo, J.M. Influence of rack slope and approaching conditions in bottom intake systems. Water 2017, 9, 65. [CrossRef]

4. García, J.T. Estudio Experimental y Numérico de los Sistemas de Captación de Fondo. Ph.D. Thesis, Universidad Politécnica de Cartagena, Cartagena, Spain, June 2016. (In Spanish)

5. García, J.T.; Castillo, L.G.; Haro, P.L.; Carrillo, J.M. Diseño de Sistemas de Captación de Fondo. V Jornadas de Ingeniería del Agua, JIA 2017. Available online: http://geama.org/jia2017/wp-content/uploads/ ponencias/tema_A/a15.pdf (accessed on 3 August 2018). (In Spanish)

6. Castillo, L.G.; García, J.T.; Haro, P.; Carrillo, J.M. Rack Length in Bottom Intake Systems. Int. J. Environ. Impact. 2018, 1, 279-287. [CrossRef]

7. Carrillo, J.M.; García, J.T.; Castillo, L.G. Experimental and Numerical Modelling of Bottom Intake Racks with Circular Bars. Water 2018, 10, 605. [CrossRef]

8. Garot, F. De Watervang met liggend rooster. Ing. Ned. Indie 1939, 6, 115-132.

9. Righetti, M.; Rigon, R.; Lanzoni, S. Indagine sperimentale del deflusso attraverso una griglia di fondo a barre longitudinali. In Proceedings of the XXVII Convegno di Idraulica e Costruzioni Idrauliche, Genova, Italy, 12-15 September 2000; Volume 3, pp. 112-119. Available online: http:/ / www.ing.unitn.it/ rigon/papers / righetti_etal.pdf (accessed on 3 August 2018). (In Italian)

10. Ghosh, S.; Ahmad, Z. Characteristics of flow over bottom racks. Water Energy Int. 2006, 63, 47-55.

11. Kumar, S.; Ahmad, Z.; Kothyari, U.C.; Mittal, M.K. Discharge characteristics of a trench weir. Flow Meas. Instrum. 2010, 21, 80-87. [CrossRef]

12. Brunella, S.; Hager, W.; Minor, H. Hydraulics of Bottom Rack Intake. J. Hydraul. Eng. 2003, 129, 2-10. [CrossRef]

13. Vargas, V. Tomas de fondo. In Proceedings of the XVIII Congreso Latinoamericano de Hidráulica, Oaxaca, Mexico, 6-10 October 1998. (In Spanish)

14. Subramanya, K. Flow in Open Channels, 3rd ed.; Tata McGraw-Hill Publishing Company: New Delhi, India, 1982; pp. 388-395.

15. Orth, J.; Chardonnet, E.; Meynardi, G. Étude de grilles pour prises d'eau du type 'en-dessous. Houille Blanche 1954, 9, 343-351. (In French) [CrossRef]

16. White, J.K.; Charlton, J.A.; Ramsay, C.A.W. On the Design of Bottom Intakes for Diverting Stream Flows. In Proceedings of the Institution of Civil Engineers; ICE Publishing: London, UK, 1972; pp. 337-345.

17. Nakagawa, H. On Hydraulic Performance of Bottom Diversion Works; Bulletin of Disaster Prevention Research Institute, Kyoto University: Kyoto, Japan, 1969.

18. Bina, K. Using dividing discharge streamline concept for estimating diverted discharge in mesh-panel bottom racks. Flow Meas. Instrum. 2018, 61, 38-48. [CrossRef]

19. Drobir, H.; Kienberger, V.; Krouzecky, N. The wetted rack length of the Tyrolean Weir. In Proceedings of the IAHR-28th Congress, Graz, Austria, 22-27 August 1999.

20. Ract-Madoux, M.; Bouvard, M.; Molbert, J.; Zumstein, J. Quelques réalisations récentes de prises en-dessous à haute altitude en Savoie. Houille Blanche 1955, 10, 852-878. (In French) [CrossRef]

21. Bouvard, M. Mobile Barrages and Intakes on Sediment Transporting Rivers, 1st ed.; Routledge: London, UK, 1992; pp. 197-233.

22. Raudkivi, A.J. Hydraulic Structures Design Manual; IAHR Monograph Balkelma: Rotterdam, The Netherlands, 1993; pp. 92-105.

23. Drobir, H. Entwurf von Wasserfassungen im Hochgebirge. Österr. Wasserwirtsch. 1981, 11, $243-253$. (In German)

24. De Marchi, G. Profili longitudinali della superficie libera delle correnti permanenti lineari con portata progressivamente crescente o progressivamente decrescente entro canali di sezione constante. Ric. Sci. Ricostr. 1947, February-March, 203-208. (In Italian) 
25. Krochin, S. Diseño Hidráulico, 2nd ed.; Escuela Politécnica Nacional: Quito, Ecuador, 1978; pp. 97-106. (In Spanish)

26. Motskow, M. Sur le calcul des grilles de prise d'eau. Houille Blanche 1957, 12, 570-580. (in French).

27. Frank, J.; Von Obering, E. Hydraulische Untersuchungen für das Tiroler Wehr. Bauingenieur 1956, 31, 96-101. (In German)

28. Bouvard, M.; Kuntzmann, J. Étude théorique des grilles de prises d'eau du type En dessous. Houille Blanche 1954, 5, 569-574. [CrossRef]

29. Castillo, L.G.; García, J.T.; Carrillo, J.M. Experimental and numerical study of bottom rack occlusion by flow with gravel-sized sediment application to ephemeral streams in semi-arid regions. Water 2016, 8, 166. [CrossRef]

30. Castillo, L.G.; García, J.T.; Carrillo, J.M. Experimental measurements of flow and sediment transport through bottom racks-influence of gravels sizes on the rack. In Proceedings of the International Conference on Fluvial Hydraulics, Lausanne, Switzerland, 3-5 September 2014; pp. 2165-2172. Available online: http: / / www.upct.es/hidrom/publicaciones/congresos/sizes_on_the_rack.pdf (accessed on 1 August 2018).

31. Bina, K.; Saghi, H. Experimental study of discharge coefficient and trapping ratio in mesh-panel bottom rack for sediment and non-sediment flow and supercritical approaching conditions. J. Exp. Therma. Fluid Sci. 2017, 88, 171-186. [CrossRef]

32. Carrillo, J.M.; Castillo, L.G.; García, J.T.; Sordo-Ward, A. Considerations for the design of bottom intake systems. J. Hydroinform. 2018, 20, 232-245. [CrossRef]

33. Frank, J. Fortschritte in der hydraulic des Sohlenrechens. Bauingenieur 1959, 34, 12-18. (In German)

34. Rouse, H. Fluid Mechanics for Hydraulic Engineers, 1st ed.; Dover Publications Inc.: New York, NY, USA, 1961; pp. 1-30.

35. Heller, V. Scale effects in physical hydraulic engineering models. J. Hydraul. Res. 2011, 49, 293-306. [CrossRef]

36. Bridgman, P.W. Dimensional Analysis, 1st ed.; Yale University Press: New Haven, CT, USA, 1922; pp. 1-88.

37. Chanson, H. Hydraulics of Open Channel Flow, 2nd ed.; Elsevier: New York, NY, USA, 2004.

(C) 2018 by the authors. Licensee MDPI, Basel, Switzerland. This article is an open access article distributed under the terms and conditions of the Creative Commons Attribution (CC BY) license (http:/ / creativecommons.org/licenses/by/4.0/). 